\title{
LA TRANSFORMACIÓN DE LA METAPHYSICA NATURALIS EN METAFOROLOGÍA
}

\author{
Luis Fernando Cardona Suárez* \\ doi:10.11144/Javeriana.uph34-68.tmnm
}

\begin{abstract}
RESUMEN
En el presente texto se examinará el sentido de la transformación kantiana de la metafísica a la luz de la metaforología de Hans Blumenberg. En un primer momento, se indicará la noción kantiana de la metaphysica naturalis que podemos encontrar en la Crítica de la razón pura, para mostrar cómo el programa de la metaforología asume esta formulación, pero tomando distancia del proyecto de la historia de los conceptos realizado por Joachin Ritter. En un segundo momento, se examinará por qué para Blumenberg la metáfora puede ser asumida como una función antropológica específica. Finalmente, en un tercer momento, se indicará también por qué el despliegue histórico de la disposición natural del hombre a plantearse preguntas que no puede contestar, pero que tampoco puede rechazar porque surgen de su propia naturaleza, realiza el devenir de la metáfora en el mundo de la vida del hombre.
\end{abstract}

Palabras clave: Kant; metafísica; Hans Blumenberg; antropología filosófica, metáfora

* Pontificia Universidad Javeriana, Bogotá, Colombia

Correo electrónico: fcardona@javeriana.edu.co

Para citar este artículo: CARDONA SUÁREZ, L.F. La transformación de la metaphysica naturalis en metaforología. Universitas Philosophica, 34(68), pp. 39-80. ISSN 0120-5323, ISSN en línea 23462426. doi:10.11144/Javeriana.uph34-68.tmnm 


\title{
THE TRANSFORMATION \\ OF THE METAPHYSICA NATURALIS IN TO METAPHOROLOGY
}

\author{
Luis Fernando Cardona Suárez
}

In this text the Kantian transformation of the meaning of metaphysics will be examined in the light of Hans Blumenberg's metaphorology. First, I will shed light on the notion of metaphysica naturalis proposed in the Critique of Pure Reason and then show how the program of metaphorology assumes this formulation, but not in the same sense as Joachin Ritter's project of a history of concepts. Second, I propose to examine why according to Blumenberg the production of metaphors can be construed as a specific anthropological function. Finally, I will argue that the historical unfolding of the natural disposition of man to pose questions that he cannot answer, nor refuse, since they arise from his own nature, constitutes the flux of metaphor in the life-world.

Key words: Kant; metaphysics; Hans Blumenberg; philosophical anthropology; metaphor 
Siempre se volverá a ella como a una amante con la que hemos reñido. Immanuel Kant

Si bien para Kant la METAFísica no es posible como ciencia, sí lo es en general como disposición natural del hombre ${ }^{1}$. Según Kant, el camino seguido hasta ahora por la metafísica ha sido "un mero tanteo, y, lo que es lo peor de todo, [un tanteo] entre meros conceptos" (CRP B XV). Al mirar la historia de lo que ha sido la realización del deseo natural del hombre de saber, del que hablaba ya Aristóteles en el libro primero de la Metafísica (980a), Kant encuentra que este deseo aplicado a lo que habitualmente se entiende como el campo de los asuntos metafísicos ha sido fuente de un constante "campo de batalla" (CRP A VIII). Los participantes en estas disputas se han visto obligados a defender, por un lado, un acceso privilegiado a objetos que están fuera del campo de la experiencia posible, cayendo en afirmaciones dogmáticas, o a sostener, por otro lado, que nada podemos decir sobre aquello que excede el límite del conocimiento teórico, hundiéndose así en un escepticismo radical, tan problemático como el dogmatismo que intentan confrontar con razones.

Pero antes de promover la investigación detenida sobre el asunto en cuestión, lo que realmente provocan estas disputas es "el hastío y el completo indiferentismo" (CRP A X)2. En este contexto, el proyecto crítico kantiano busca alcanzar una orientación adecuada para abordar preguntas que no podemos

1 La Crítica de la razón pura demuestra de manera clara que no es posible "un conocimiento racional especulativo enteramente aislado que se eleva por completo de las enseñanzas de la experiencia, y que lo hace mediante meros conceptos" (CRP B XIV), pues dicho conocimiento no ha contado ni puede contar, por definición, con una contrastación empírica que asegure la certeza de sus aseveraciones.

En el presente trabajo se seguirá la traducción de la Crítica de la razón pura realizada por el profesor Mario Caimi y publicada en edición bilingüe por el Fondo de Cultura Económica de México y la Universidad Autónoma de México en 2009. Como es la costumbre, la cita se indica con la abreviatura CRP, seguida de la página del original en la edición A (1781) o B (1787) según corresponda.

2 Así, con el paso del tiempo se ha llegado incluso a "fingir indiferencia con respecto a investigaciones cuyo objeto no puede ser indiferente a la naturaleza humana" (CRP A X). 
contestar, pues sobrepasan nuestra posibilidad de respuesta, pero a las que tampoco podemos renunciar, ya que no podemos ser indiferentes frente a lo que aquí está en juego. Obviamente, esto implica reconocer con toda claridad el "singular destino" (CRP A VII) que nos atraviesa como los seres racionales que somos. No cabe duda de que el resultado de este proceder crítico encierra igualmente una paradoja: no es posible la metafísica como conocimiento científico de los objetos que están a la base de dichas preguntas, pero no podemos renunciar a ella. Esta paradoja lleva a Kant a sostener que los asuntos que han entrado en juego en la historia de la metafísica, y que en cuanto tal han sido con frecuencia objeto de enormes disputas, son realmente expresión de nuestra propia condición humana, por lo que siempre regresaremos a ellos ${ }^{3}$.

La realidad de la metafísica coincide entonces con la propia disposición natural del hombre (Naturanlage), no con su efectualidad histórica como ciencia. La metafísica es real en la medida que atiende, no a partir de meros conceptos y según su proceder dogmático, a cuestiones últimas que son, ciertamente, "los asuntos humanos universales y al provecho que el mundo extrajo hasta ahora de las doctrinas de la razón pura" (CRP B XXXII). Estos intereses últimos ${ }^{4}$ han girado normalmente en torno a dos asuntos fundamentales: la existencia de Dios y la posibilidad de una vida futura. Antes de referirse a objetos fenoménicos y, por tanto, susceptibles de estar determinados por experiencia alguna, estos asuntos son "dos artículos de fe [Glaubenartikel]" (CRP B 858). A estos dos artículos podemos anexar también la preocupación por alcanzar un conocimiento adecuado de la totalidad de los fenómenos expresada en la idea de mundo, tarea

3 En la introducción a la Crítica de la razón pura Kant condensa nuestra condición frente a estos asuntos abordados bajo el rótulo de metafísica de la siguiente manera: "Ahora bien, hay que considerar esta especie de conocimiento también, en cierto sentido, como dada; y la metafísica es efectivamente real, sino como ciencia, sí empero como disposición natural (metaphysica naturalis). Pues la razón humana, acicateada por su propia necesidad, sin que la mueva a ello la mera vanidad de [pretender] saber mucho, progresa inconteniblemente hasta aquellas preguntas que no pueden ser respondidas por ningún uso empírico de la razón ni por principios tomados de allí, y así, en todos los hombres, tan pronto la razón se ha ensanchado en ellos hasta la especulación, ha habido siempre efectivamente alguna metafísica [irgend eine Metaphysik] y seguirá estando allí siempre" (CRP B 21).

4 Por definición, estos intereses últimos no pueden estar subordinados a "ningún otro superior" (CRP B 826), ni a las determinaciones históricas de su realización efectiva. Este asunto lo examinaremos más adelante. 
esta que justamente Kant quería emprender bajo la forma de una "metafísica de la naturaleza [Metaphysik der Natur]" (CRP A XXI), después de haber realizado las tareas de la Critica de la razón pura. Siguiendo pues la tradición más clásica de la metafísica, podemos decir que los tres asuntos fundamentales que aquejan al hombre, que no obstante no pueden ser resueltos con ciencia alguna, se condensan en estos tres términos: mundo, Dios y vida futura. Estos asuntos seguirán siendo problemáticos, aunque lleguemos a una cierta consumación histórica del modelo más radical de explicación científica.

En efecto, no podemos desprendernos de aquello que realmente inquieta a nuestra razón y que en cuanto tal articula nuestro mundo vital histórico. Al finalizar la arquitectónica de la razón pura, Kant presenta grosso modo la idea general de la metafísica bosquejada por la crítica:

[s]e puede estar seguro de que por muy remilgados o desdeñosos que se muestren los que no saben juzgar a una ciencia según la naturaleza de ella, sino únicamente por sus efectos accidentales, siempre se volverá a ella como a una amante con la que hemos reñido. (CRP B 877-878)5

Esta idea general coincide, en efecto, con la filosofía en sentido propio: ser la maestra de la humanidad, pues solo así podrá seguir siendo "la consumación de toda cultura de la razón humana" (CRP A 850). Al lado de un "conocimiento por construcción de los conceptos" (CRP B 741), esto es, el conocimiento propiamente científico ${ }^{6}$, se ha dado también el filosófico que "considera lo particular solo en lo universal" (CRP B 742). Esta tensión ha determinado, sin duda, la comprensión histórica de la filosofía. La historia de la filosofía se ha visto afectada, por un lado, por la búsqueda del perfeccionamiento de un sistema

5 No obstante, este trabajar incansablemente no lo entendemos aquí como un mero ejercicio teórico o puramente conceptual, sino como una realización efectiva de y en la metáfora. Este asunto se aclarará más adelante, al momento de estudiar la metaforología como un proceder técnico propio del lenguaje traslaticio que caracteriza a los tropos y, en particular, al discurso de la metáfora.

6 Para Kant, construir un concepto significa "exhibir a priori la intuición que le corresponde. Para la construcción de un concepto se requiere, pues, una intuición no empírica, que por consiguiente, como intuición, es un objeto singular, pero que, sin embargo, como construcción de un concepto ([como construcción] de una representación universal) debe expresar, en la representación, validez universal con respecto a todas las intuiciones posibles que hayan de estar bajo ese concepto" (CRP A 713). El ejemplo más claro de lo que significa "construcción de un concepto" lo podemos encontrar entonces en uno de los objetos característicos de la geometría, el triángulo. 
científico de conocimientos que no tiene otro objetivo más que "la unidad sistemática de ese saber, por tanto, la perfección lógica del conocimiento" (CRP B 866). A este camino Kant lo denomina "concepto escolástico [Schulbegriff]" (CRP A 838) de la filosofía. Sin embargo, por otro lado, se ha abierto también el camino hacia la realización histórico-efectiva de un "conceptus cosmicus de la filosofía [Weltbegriff]” (CRP B 866), encarnado justamente en la idea del filósofo.

Según este conceptus cosmicus, la filosofía sería "la referencia de todo conocimiento a los fines esenciales de la razón humana (teleologia rationis humanae), y el filósofo no es un artista de la razón [Vernunftkünstler], sino el legislador de la razón humana [Gesetzgeber der menschlichen Vernunft]" (CRP B 867). Como vemos, este Weltbegriff coincide realmente con la idea central de una metaphysica naturalis que queremos aquí bosquejar en clave metaforológica. Ahora bien, el retorno a la "amante", de la que habla Kant al final de la Crítica de la razón pura, no implica simpliciter la reactivación de una determinada escuela, sino su realización efectiva en un mundo de la vida histórico determinado. Es decir, el permanente retorno a la metaphysica naturalis no es otra cosa más que su realización efectiva en un mundo de vida histórico dado o, como le gusta señalar a Hans Blumenberg, en el mundo de la vida del hombre ${ }^{8}$. Obviamente, los caminos de retorno son distintos, aunque los asuntos sean los mismos. A continuación, queremos mostrar por qué para Blumenberg "la desaparición de la metafísica llama de nuevo a la metafórica a ocupar su lugar" (2003a, p. 257).

7 Este retorno no lo entendemos aquí como un elemento puramente recesivo en la historia del pensamiento occidental, tampoco como un trauma que no hemos podido superar, dado que aún no hemos contado con las herramientas adecuadas para curarnos definitivamente de las pretensiones de la metafísica. Más bien, lo entendemos como la efectiva realización metacinética de las metáforas absolutas que conforman una totalidad histórica de sentido. Este asunto se entenderá, más adelante, cuando se aborde la dimensión histórica de la metaforología.

8 En el presente trabajo queremos mostrar la conexión profunda entre el proyecto crítico kantiano y la metaforología blumenberguiana, pero debemos tener en cuenta aquí que "lo necesario para la conservación [del hombre] siempre está dominado por la conciencia de la contingencia. La filosofía sólo puede recordar algo que quizá tenga que ver con eso, pero no podrá estar segura. La empresa filosófica de Blumenberg tiene así todo el aspecto de la vieja metafísica kantiana. En realidad es una empresa crítica, sólo que en lugar de Kant usa a Husserl de punto de partida. O mejor, que intenta reconstruir una filosofía que vinculará a Kant y Husserl de forma adecuada. Este vínculo tendría que ver con la activación de la premisa antropológica respecto de una crítica de la razón" (Villacañas, 2014, p. 69). 
Blumenberg (2003A) Concibe su METAForología como una investigación arqueológica del subsuelo de la significatividad, en la medida que "las metáforas pueden ser también elementos básicos del lenguaje filosófico” (p. 44). En este sentido, la metaforología se expresa como un proyecto alternativo a la historia del concepto tal como proponía desarrollarla Joachin Ritter en su famoso Historische Wörterbuch der Philosophie. Podemos decir entonces que la metaforología es una vía alternativa, pero no porque se ocupe de la metáfora y sobre todo de la historia de los conceptos con conceptos, sino ante todo porque representa la tesis arqueológica según la cual la significatividad opera siempre en un subsuelo metafórico9. Blumenberg buscaba inicialmente integrar en la historia del concepto las perspectivas arqueológicas y metaforológicas, para de este modo delinear un verdadero proceder sistemático. En este sentido, su proyecto filosófico podría ser caracterizado aquí como una descripción histórica de la técnica con la cual el hombre enfrenta su propia existencia ${ }^{10}$. El complejo acceso analítico discursivo que enlaza metaforología e historia del concepto apunta también a la

9 Hans Blumenberg (1971 p. 163) intenta delinear para la publicación del primer tomo del diccionario histórico de la filosofía la relación entre la metaforología y la historia de los conceptos.

10 En una de sus obras póstumas publicada recientemente Blumenberg (2013a) señala la dificultad que se debe asumir, cuando se quiere hablar, por ejemplo, de una historia de la técnica: "La mayoría de los intentos de obtener aspectos filosóficos para el problema de la técnica pueden remitirse, en esencia, a dos enfoques. El primero quedaría expresado en el enunciado de que la técnica es un fenómeno específicamente humano. Ya el hecho de que los hallazgos de instrumentos y los atisbos del dominio del fuego tengan, para el paleontólogo y el antropólogo, el valor de claros testimonios sobre el carácter humano de los restos fósiles presupone que el Homo sapiens es documentado como Homo faber. La técnica se halla enraizada en la naturaleza del hombre y es, por tanto, tan antigua como el hombre mismo. Con esto puede muy bien conectar la antropología filosófica y seguir preguntando por el modo de fundamentar esta relación, cómo, por ejemplo, la particularidad del equipamiento biológico del ser humano nos hace comprender todo el complejo de rendimientos suyos como una condición de su existencia. El segundo enfoque tomaría la técnica como un fenómeno histórico. Éste incluye plenamente el aspecto antes mencionado, pero trascendiéndolo, al no quedar absorbida la técnica, desde este punto de vista, por la funcionalidad instrumental de asegurar existencialmente y satisfacer las necesidades elementales del hombre. Una cosa es si el ser humano desarrolla un comportamiento técnico bajo la presión de las necesidades de existencia y otra distinta si percibe y asume su tecnicidad como un tema y una asignatura de su autointerpretación y su autorrealización. [...] Podemos dejar abierta, [...] la cuestión de si la autoconcepción del hombre realizada en la tecnificación fue algo originario y radicalmente fundamentador, es decir, un concepto históricamente espontáneo, o si también aquí precedió una imperiosidad comparable a la situación biológica de partida, aunque esta vez, es cierto, de orden 
reconstrucción de la génesis histórica y sistemática de fenómenos modernos emblemáticos, tales como la configuración histórica de la Modernidad o la imagen copernicana del mundo.

Afirmar que la teoría blumenbergiana de la metáfora puede ser asumida como una tarea arqueológica no significa que se esté identificando sin más el proceder de Blumenberg con el de Derrida ${ }^{11}$, ya que la metáfora absoluta de Blumenberg y el subsuelo derridiano de los tropos no describen un mismo fenómeno. La primacía de lo histórico-ontológico de Derrida se puede complementar con la descripción existencial del mundo de la vida del hombre. Mientras Blumenberg investiga con frecuencia una metáfora particular, Derrida acentúa más bien la mutua interrelación de las metáforas entre ellas y con el lenguaje. Al contrario, Blumenberg separa la dinámica histórica de la metafórica y de la lógica, poniendo en otro lugar histórico una determinada metáfora; de esta manera, centra su interés en la significación pragmática de las metáforas que para Derrida permanece siempre oscura. Pero al igual que Derrida, Blumenberg describe de manera positiva la relación que existe entre la metafórica absoluta y la metafísica.

En la literatura especializada sobre Blumenberg se ha dado una gran polémica en torno al desarrollo de su proyecto metaforológico que va desde sus trabajos tempranos de 1957 sobre la metáfora de la luz hasta el despliegue de su posterior teoría de la inconceptualidad (Theorie der Unbegriffichkeit) de 1979. Más allá de este debate, queremos sostener aquí que la metaforología puede ser comprendida como una unidad en sí misma diferenciada, aunque permeada por desarrollos y pesos diferenciados. En particular, no vemos una ruptura fundamental entre

intelectual, a la que había que dar una respuesta cuya forma más pregnante quedaba realizada justo en el fenómeno de la técnica" (pp. 107-108).

11 Cuando acercamos a Blumenberg y Derrida debemos tener en cuenta los riesgos que obviamente se corren, sobre todo el de simplificar esquemas distintos de comprensión para hacer viable dicha relación, oscureciendo con ello las diferencias para resaltar las aparentes proximidades. Más bien, lo que debemos intentar es el careo de "dos a-stigmatismos (literalmente, la destrucción desenfocada de toda indivisibilidad estigmática en Derrida y los arreglos en la niebla de una experiencia del apagón de la simultaneidad en Blumenberg), [buscando] la posibilidad de una historia (demultiplicada en historietas) de la experiencia humana, que asuma, sin amortización dialéctica y con el detallismo fenomenal de la descripción, de una posibilidad com-plicada, la doble asignación que somos: principio de ruina y estabilización contingente, síntoma y mathema, tumba y rumba, ambición trascendental y tropiezo, estrofa y catástrofe: casi una sonata, casi una materia" (López, 2013, pp. 111-112). 
los textos tempranos de la metaforología y los de la posterior teoría de la inconceptualidad, como sostiene por ejemplo Philipp Stoellger (2000, p. 253). En su confrontación con el proyecto filosófico de la historia del concepto, Blumenberg (1971) busca delinear el campo de posibilidad de la metáfora, señalando que "el espacio de la metáfora es el espacio de la imposible formación del concepto, la fracasada o la que todavía no logra consolidarse. La norma de la conceptualidad consiste en la orientación anticipada que, de su parte, debe necesariamente radicar fuera del campo de la norma y de su sistemática” (p. 171). Como vemos, Blumenberg en esta declaración programática le asigna a la metáfora una función tanto en el terreno previo (vor) como en el posterior (nach) de la conceptualidad. En este sentido, la metáfora se encuentra en el terreno previo del concepto: "La filosofía que ha tenido que comenzar cada vez con lo incomprensible y lo preconceptual, debe soportar al mismo tiempo la tensión entre las formas de articulación de lo incomprensible y lo preconceptual" (Blumenberg, 2001a, p. 139). Aquí se mezclan las dos dimensiones fundamentales de la metáfora ${ }^{12}$ : por un lado, las metáforas pueden tener una aplicación de modo provisional en la ciencia, por ejemplo, en el proceso de formación de conceptos aún no consolidados, donde las descripciones conceptuales no son del todo posibles debido a un saber que todavía falta. Estas afirmaciones metafóricas iniciales o modelo podrán ser reemplazadas más tarde por descripciones conceptuales. Pero, por otro lado, se indica también que la metáfora aparece en muchas ocasiones como un medium poco rígido tanto para lo nuevo como para la articulación de la experiencia del mundo de la vida. Por esta razón, Blumenberg habla a manera de contraste de una arquitectónica fija de los sistemas conceptuales (Blumenberg, 2001a, p. 139) $)^{13}$.

Pero la metáfora interviene también allí donde la formación del concepto fracasa o es imposible, es decir, donde el concepto ya no es más suficiente para

12 Estas dos dimensiones muestran el uso que le da Blumenberg al término metáfora absoluta como un modelo en función pragmática, pues llena un vacío, en la medida que es "una forma de significación indirecta” (Gehring, 2014, p. 206).

13 Aquí podemos ver que el interés de Blumenberg por la metáfora realiza un giro claramente viconiano y romántico. Sus expectativas en la sensibilidad metafórica de la metáfora obran también en las estructuras sintácticas profundas trabajadas por Derrida en su perspectiva deconstructiva, pues ellas siempre se desplazan hacia las metáforas y hacia el descubrimiento del campo de la imagen. 
cumplir su tarea de significación. Esto sucede no solo en el caso de la metafísica, cuando el pensar se dirige a aquellos objetos que son muy grandes para que pueda haber una captación conceptual directa ${ }^{14}$. En efecto, este horizonte total está formado por los objetos clásicos de la metafísica como Dios, el ser y el mundo (Blumenberg, 2003a, p. 46), la historia, la vida, el hombre, la verdad (Blumenberg, 2003a, p. 42). El interés arqueológico-conceptual de Blumenberg en la metáfora tiene entonces un respaldo metafísico. Por esta razón, señala que su metaforología es una vía para atender aquellos asuntos que habitualmente consideramos como problemas metafísicos, pero de los cuales no podemos tener una respuesta definitiva: “Las metáforas absolutas 'responden' a preguntas aparentemente ingenuas, incontestables por principio, cuya relevancia radica simplemente en que no son eliminables, porque nosotros no las plantamos, sino que nos las encontramos como ya planteadas en el fondo de la existencia" (Blumenberg, 2003a, p. 62) $)^{15}$.

En los dos casos anteriormente anotados -tanto para el desarrollo del trazado fundamental de la objetualidad de un objeto (el ser del ente) como también cuando el pensar se refiere al todo de un campo de objetos (el existente en totalidad)-, la metáfora ayuda y fija una estructura agregada al interior de la conceptualidad que entra aquí en juego. Es decir, la metáfora pone aquella "orientación anticipada” (Blumenberg, 1971, p. 171) para la conceptualidad, de la que Blumenberg habla en la segunda frase de la cita con la que iniciamos nuestra reflexión. En la medida que la elaboración conceptual se mueve solo al interior de

14 Siguiendo a Kant, esto lo señala Blumenberg (1995) mostrando que "en la historia de la recepción de las metáforas hay, cuanto más pregnante y diferenciado se ha vuelto el patrimonio imaginario, un punto en el cual parece generarse un estímulo extremo a tratar sin consideración alguna el modelo encontrado y a experimentar sobre él el insuperable procedimiento de una inversión" (p. 91). Por esta razón, el uso de metáforas es imprescindible en el campo de la metafísica, constituyendo así su lenguaje más propio.

15 Inmediatamente después de esta indicación Blumenberg (2003a) realiza la siguiente anotación metodológica: " $[\mathrm{t}]$ enemos que tener aquí presente que una metaforología no puede llevar a un método para el uso de metáforas o para habérselas con las preguntas que se manifiestan en ellas. Al contrario: como cultivadores de la metaforología nos hemos privado ya de la posibilidad de encontrar en las metáforas 'respuestas' a esas preguntas incontestables. La metáfora como tema de una metaforología en el sentido que aquí nos ocupa es un objeto esencialmente histórico, de modo que el valor de su testimonio tiene como presupuesto que el propio hablante no poseía ninguna metaforología, y ni siquiera podía poseerla" (p. 62. Las cursivas son mías). Este asunto se examina más adelante. 
los diseños prefigurados por la metáfora, ella se convierte así en la "norma de la conceptualidad” (Blumenberg, 1971, p. 171). Esto sucede así porque el proyecto metafórico se transforma en un horizonte constitutivo del concepto que se encuentra fuera del campo de la norma (Blumenberg, 1971, p. 171), dado que la norma forma el concepto y que, por tanto, cada campo diferente de su realización elabora la conceptualidad que le es propia.

En este contexto, Blumenberg (2003a) denomina el objeto temático de su metaforología con la expresión "metáfora absoluta" (p. 44) 16 $^{16}$ La caracterización de esta metáfora como absoluta -del latín absolutus, que se puede traducir como lo separado, lo independiente y encerrado en sí- sugiere que no se trata en este caso de la metáfora en el sentido aristotélico tradicional y tampoco en el sentido derridiano de los tropos de base. Blumenberg describe las metáforas absolutas como los "elementos básicos del lenguaje filosófico, 'transferencias' que no se pueden reconducir a lo propio, a la logicidad" (Blumenberg, 2003a, p. 44). Es decir, estos elementos básicos son solo "transferencias" (Übertragungen) entre comillas, ya que la semejanza afirmada en ellas no se puede verificar por medio de un horizonte total que resulta teóricamente inabordable ${ }^{17}$. Por esta razón, permanece siempre abierto un resto conceptual inalcanzable. Blumenberg señala, de este modo, que la metáfora absoluta posee un mayor rendimiento que simplemente "suscitar 'placer' al comunicar la verdad" (Blumenberg, 2003a, p. 44). El descubrimiento de estos elementos básicos de origen metafórico tiene enormes

16 En el interés específico de conocimiento podemos ver que Blumenberg no desarrolla, al igual de lo sucedido en Derrida, una teoría general de la metáfora, esto quiere decir que los tropos son el objeto de su metaforología.

17 En este punto Blumenberg (2003a) cita el concepto central de la teoría aristotélica de la metáfora. Para una adecuada comprensión del poder de la metáfora debemos tener presente su relación con la lógica de la fantasía y el tratamiento del discurso traslaticio: "[e]sta clasificación tradicional de la metáfora en la teoría de los ornamentos del discurso público no es casual para la Antigüedad, el lógos igualaba por principio al todo del ente. Kósmos y lógos eran términos correlativos. Aquí, la metáfora no tiene la forma de enriquecer la capacidad de los medios de expresión; no es más que un medio de conseguir que el enunciado sea eficaz, que afecte e interese a sus destinatarios políticos y forenses. La perfecta congruencia de lógos y kósmos excluye que el discurso traslaticio pueda producir algo que el nombre soberano no lleve igualmente a cabo. En el fondo, el orador, el poeta no pueden decir nada que no pudiera presentarse también de forma teórico-conceptual; lo específico, en su caso, no es el qué, sino solo el cómo" (p. 43). 
consecuencias para la comprensión de la filosofía. Como sucede en Derrida, Blumenberg describe estass consecuencias del siguiente modo:

Si fuese posible mostrar que se dan tales "transferencias" que habría que llamar "metáforas absolutas", la fijación y análisis de su función enunciativa, conceptualmente irresoluble, constituiría una pieza esencial de la historia de los conceptos (en este amplio sentido del término). [...]. En general, la exhibición de metáforas absolutas debería permitirnos pensar de nuevo a fondo la relación entre fantasía y lógos, y justamente en el sentido de tomar el ámbito de la fantasía no solo como sustrato para transformaciones en la esfera de lo conceptual -en donde, por así decirlo, puede ser elaborado y transformado elemento tras elemento, hasta que se agote el depósito de imágenes-, sino como una esfera catalizadora en la que desde luego el mundo conceptual se enriquece de continuo, pero sin por ello modificar y consumir esa reserva fundacional de existencias. (2003a, pp. 44-45)

En este sentido, el objeto de la metaforología son los elementos básicos no conceptuales del lenguaje filosófico que forman el fundamento u horizonte de cada elaboración conceptual y que, a la vez, predeterminan el modo de dicha elaboración, es decir, su cómo. Por esta razón, Blumenberg (2003a) caracteriza su empresa en los siguientes términos:

[1]a metaforología intenta acercarse a la subestructura del pensamiento, al subsuelo, al caldo de cultivo de las cristalizaciones sistemáticas, pero también intenta hacer comprensible con qué 'coraje' se adelanta el espíritu en sus imágenes a sí mismo y cómo diseña su historia en el coraje de conjeturar. (p. 47)

La metaforología articula, entonces, una doble tarea: penetrar en el subsuelo de nuestras configuraciones conceptuales y mostrar también el coraje necesario para emprender este acercamiento. Así, podemos decir que la metaforología es una cierta arqueología de nuestra conceptualidad más básica ${ }^{18}$, en la medida que las metáforas absolutas son "el caldo de cultivo de cristalizaciones sistemáticas" (Blumenberg, 2003a, p. 47). Veamos con más cuidado esta articulación.

18 Felix Heidenreich (2005, pp. 84-97) ha mostrado con amplitud la conexión que podemos establecer entre el proyecto de Blumenberg de adelantar la vía de la metaforología como respuesta a la historia de los conceptos y la arqueología en sentido derridiano. Esta aproximación entre metaforología y arqueología la podemos encontrar también en los trabajos de Anselm Haverkamp (2007, p. 244). 


\section{El camino arqueológico de la metafísica como función antropológica}

Para comprender el alcance de la relación que aquí queremos establecer entre metaforología y arqueología, se requiere examinar con más cuidado la proximidad que podemos encontrar entre el tropo fundador del pensamiento filosófico y la metáfora absoluta. Derrida desarrolla la idea del tropo fundador en el terreno de una perspectiva histórica. Según él, hubo antes un tiempo, al comienzo de la filosofía griega, donde no era posible establecer una diferencia entre conceptos y metáforas, porque el lenguaje filosófico aún no se había desplegado plenamente. En este tiempo aparecieron expresiones que Derrida denomina "tropos fundadores" o "conceptos fundadores", que no se separaban entre sí y que, más bien, impregnaron el lenguaje filosófico configurando la theoria, el eidos y el logos, ya que "las pasiones hablaron antes que las razones" (Derrida, 2010, p. 271). Esta perspectiva histórica complementa la concepción de Blumenberg de la metáfora absoluta, ya que señala que el pensar debe retroceder al horizonte total de sentido -la verdad, la vida, el mundo- no accesible teóricamente y regresar, de este modo, al tiempo primitivo de formas de lenguaje no conceptual.

Aquí el punto de encuentro entre Derrida y Blumenberg es, justamente, el papel que tiene la "representación cataléptica" ${ }^{19}$ en la configuración de los objetos tradicionales de la filosofía, ya que muestra la tendencia de captar en cada momento la cosa misma a partir de un viraje radical del pensamiento. La dinámica del pensar consiste pues en desplegar la representación cataléptica. Blumenberg sintetiza el carácter cataléptico de la metáfora absoluta con la siguiente formulación: la metáfora absoluta, esto es, la metáfora independiente y

19 Blumenberg describe el descubrimiento de la representación cataléptica en el estoico de la siguiente manera: "Se precisa ya de toda la fuerza de la evidencia para constreñir al sujeto estoico, que persevera con desconfianza en la posición básica de la $\varepsilon ́ \pi \circ \chi \eta ́$ a dar su asentimiento a lo representado, a la $\sigma v \gamma \varkappa \alpha \tau \alpha \dot{\imath} \varepsilon \sigma \iota \varsigma$. Esta constricción se describe bajo el concepto de la 'representación aprehensiva' [o 'capturante'], de la $K \alpha \tau \alpha \lambda \varepsilon \pi \tau \iota \varkappa \eta ́ ~ \Phi \alpha \nu \tau \alpha \sigma \iota \alpha$ [representación cataléptica]; pero no tiene nada de unívoco quién captura a quién. En el sentido originario de Zenón, parece que es 'cataléptica' la representación que capta el objeto en sí 'mismo', dominándolo por entero, trayéndolo a la presencia en la plenitud de sus concretas características. Más tarde parece haber emergido la duplicidad de la 'representación cataléptica': el objeto de la $\varkappa \alpha \tau \alpha ́ \lambda \varepsilon \psi \iota \varsigma$ es el entendimiento captado dominado por la evidencia de la representación. Ahora bien, para nuestro tema es del mayor interés que este desplazamiento conceptual se realice manifiestamente al hilo de las representaciones metafóricas" (Blumenberg, 2003a, pp. 53-54). 


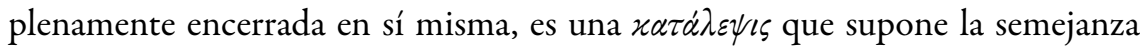
que la afirma para describirla. Podemos ver el sentido de este movimiento traslaticio cuando examinamos una de las metáforas absolutas más emblemáticas del pensar filosófico, la clásica metáfora de la luz: "así como la luz se muestra y al mismo tiempo se muestran los objetos que están en la luz, también la representación se muestra a sí misma y lo que evoca" (Blumenberg, 2003a, p. 54). En este contexto, podemos decir que la metáfora se da a sí misma la totalidad que reclama ser definida, de modo que es realmente la tautología de su propia posición. Las metáforas absolutas ocurren como determinaciones, pero reemplazan estas determinaciones, pues ciertamente van más allá ${ }^{20}$.

Así pues, las metáforas absolutas que fueron encontradas para el mundo dan a este campo abierto de la experiencia una forma (consistencia) y, ante todo, la hacen accesible de modo universal. En el mismo momento de esta emergencia deviene el mundo, pero también aquello que podemos llamar un hecho textual ${ }^{21}$.

20 Ahora bien, sobre la base de este rendimiento encubierto de la representación cataléptica, la metáfora absoluta es, en efecto, la confirmación tautológica de su propia afirmación. La situación empírica, que es siempre abierta e hipotética, ha perdido aquí la consistencia que solo en un texto podría existir. Esta consistencia está establecida por una metáfora, esto es, por una figura sustituta del discurso, que transforma la situación referencial situada en el balance entre la ficción y el hecho en un hecho justamente forjado de palabra. En Paradigmas para una metaforología Blumenberg señala el carácter traslaticio del discurso metafórico siguiendo justamente la teoría kantiana del símbolo, particularmente lo anotado por Kant en el parágrafo 59 de la Crítica del juicio, donde se muestra que las intuiciones que se ponen a priori bajo conceptos pueden ser también símbolos en la medida en que contienen exposiciones indirectas del concepto, procediendo entonces por analogía en la cual el entendimiento lleva a cabo una doble tarea: aplica el concepto al objeto de una intuición sensible y, a la vez, aplica "la mera regla de la reflexión sobre aquella intuición a un objeto totalmente diferente, del cual el primero es tan sólo símbolo" (CJ B 256; Ak. V 352. Se cita aquí la Crítica del juicio con la abreviatura acostumbrada $\mathrm{CJ}$, indicando la página del original en la edición en A o B, seguida de la correspondiente página de la edición crítica de la Academia). El símbolo es entonces expresión del movimiento traslaticio propio de la metáfora, esto es, de un proceso de sustitución que solo es posible realizar como "procedimiento del transporte de la reflexión" (Blumenberg, 2003a, p. 45).

21 De modo paradójico, esta figura retórica confiere al objeto de referencia un significado textual y con ello lo priva de su carácter prefigural inmediato. Este acto paradójico es el verdadero rendimiento de la posición de la metáfora. En la medida que la metáfora absoluta actúa como descripción de una situación empírica que es abierta o hipotética, capta esta situación que está puesta en cada determinación que es parafigural. A través de esta determinación la situación parafigural se convierte en el referente de una imagen, esto es, un hecho literal (literal fact). En este sentido, la orientación anticipada que expresa las metáforas absolutas para una posible conceptualidad es ciertamente la representación de un orden de una situación previamente abierta o hipotética o de 
Blumenberg señala el carácter de esta posición de la metáfora absoluta, indicando que en la metaforología se hace comprensible "con qué 'coraje' se adelanta el espíritu en sus imágenes a sí mismo y cómo se diseña su historia en el coraje de conjeturar" (Blumenberg, 2003a, p. 47). Es decir, en las metáforas absolutas el espíritu se proyecta de manera anticipada hacia una orientación transversal, el mundo (Blumenberg, 1971, p. 171). Ahora bien, el proyecto cataléptico o el carácter de posición de la metáfora absoluta lo podemos ver operando con claridad en lo que Blumenberg llama "metafórica explosiva [Sprengmetaphorik]" (2003a, p. 241 ${ }^{22}$. La metafórica explosiva fue ampliamente desarrollada en la tradición de la teología negativa de la Antigüedad tardía. Se trata de una metafórica absoluta que ofrece una metáfora para Dios, pero que a la vez cuestiona su insuficiencia para poder entender lo que pretende captar, de modo tal que se hace necesario que dicha captación sea de nuevo retirada. En este sentido, podemos decir que la metafórica explosiva es realmente expresión del dilema elemental de aquella teología negativa que se sentía obligada a "hablar continuamente de Dios sin sentirse capaz de decir algo sobre él” (Blumenberg, 1995, p. 106).

Para Blumenberg, Nicolás de Cusa ha desplegado la representación más clásica de la coincidentia oppositorum para pensar la esencia de Dios sin tener representación alguna de ella (Blumenberg, 1995, p. 106), mostrando cómo en las cosas visibles hay ya imágenes de las invisibles ${ }^{23}$. Lo que aquí es "vivenciable" a

un objeto parafigural que, como norma así constituida, se convierte, a su vez, en su elaboración conceptual (Blumenberg, 1971, p. 171).

22 Con la expresión alemana Sprengmetaphorik Blumenberg (2003a) quiere mostrar el mayor rendimiento metaforológico de la teología negativa de la Antigüedad tardía y del Cristianismo, donde la metáfora misma violenta la intuición: "El medio de explosión de esta metafórica es el concepto de infinitud, su modelo más duradero la fórmula, fórmula que se hizo pasar por hermética, del Liber XXIV philosophorum [Libro de los veinticuatro filósofos]: Deus est sphaera infinita, cuius centrum ubique, circumferentia nusquam est [Dios es una esfera infinita cuyo centro se halla en todas partes y su circunferencia en ninguna]" (Blumenberg, 2003a, p. 242).

23 Para ello, Cusa recurre a un experimento muy sencillo: “[d]ejar, por ejemplo, que el radio de un círculo se haga infinitamente pequeño, con lo que la figura se convierte en punto, y así pierde su 'esencia', o bien dejar que crezca infinitamente, con lo que la circunferencia se transforma en línea recta y la figura deja también de ser ella misma” (Blumenberg, 2003a, p. 243). Como vemos, la metafórica de la explosión se realiza aquí como experimento. Este experimento Blumenberg lo describe de la siguiente manera: “[a]rrastra la intuición a un proceso en el que ésta comienza por ser capaz de seguir (por ejemplo, pensar el radio de un círculo duplicado y aumentado cada vez más), pero para tener que abandonar -y esto se entiende como 'rendirse' - en un punto determinado 
partir de la perspectiva metaforológica es justamente el carácter de la posición aporética de la metafórica absoluta, que a través de su proyecto abre y constituye un horizonte total de sentido desconocido o un objeto parafigural, a saber, la trascendencia. Pero en la metafórica explosiva se muestra tan solo una característica de toda metafórica absoluta, la que indica que su posición sobrepasa el límite de la aplicación teórica; pero, como hemos visto antes, permanece en dicha posición, por supuesto, el carácter aporético de este sobrepaso.

Al lado de la necesidad estructural de la experiencia conceptual surge también en la metáfora absoluta una necesidad antropológica ${ }^{24}$ que se abre camino de manera particular en casos determinados. Según Blumenberg, en su inaccesibilidad teórica al hombre se le impone como un consuelo la pregunta por el horizonte total de sentido de su experiencia, como Dios, el mundo y la vida. En esta perspectiva las metáforas absolutas son respuestas aporéticas a preguntas incontestables pero existencialmente apremiantes, cuya relevancia radica en que no son eliminables, porque nosotros no las ponemos, y en que se hallan como "ya planteadas en el fondo de la existencia” (Blumenberg, 2003a, p. 62). Blumenberg pone entre comillas estas respuestas, cuando se refiere a la pretensión de la metafísica de ofrecer respuestas fundamentales, pues quiere indicar con ello el estatus precario de las respuestas a preguntas incontestables, que no son otra cosa más que posiciones sin fondo que interpelan la existencia. Estas preguntas son, por decirlo así, "la representación exacta de la función de la 'metáfora absoluta', que irrumpe en el hueco y en la casilla vacía abstracto-conceptualmente irrellenable, para pronunciarse a su modo" (Blumenberg, 2003a, p. 238). En este sentido, el impulso de querer emprender una respuesta sin esperanza teórica a preguntas incontestables es ciertamente una necesidad antropológica: "[q]ué sea propiamente el mundo: esa cuestión, la menos irresoluble de todas, es sin embargo al tiempo

(por ejemplo, pensar el mayor de los radios posibles, o mejor el radio infinito de un círculo). Aquí lo interesante es hacer por así decir 'vivenciable' la trascendencia, como límite de la realización teórica y, eo ipso, como exigencia de modos heterogéneos de representación" (Blumenberg, 2003a, pp. 241-242).

24 Oliver Müller (2005, pp. 141-173) ha demostrado de manera detallada la necesaria articulación en el pensamiento de Blumenberg entre teoría de la cultura, antropología y metaforología a partir de la idea central del cuidado. Igualmente, Heidenreich (2005, pp. 25-43) ha señalado cómo la metaforología tiene una enorme implicación antropológica. 
la que nunca puede quedar irresuelta y, por ello, la siempre decidida" (Blumenberg, 2003a, p. 65) 25 .

Para entender este viraje de la metaforología hacia la metafísica, resulta instructivo examinar en breve la proximidad de la formulación aporética blumenbergiana de las preguntas incontestables, y que a pesar de todo interpelan al hombre, con la indicación kantiana que da inicio a la primera edición de la Critica de la razón pura $^{26}$. Las preguntas que aborda Kant, en efecto, las más básicas de la metafísica. Se trata de aquellas preguntas que, según Blumenberg (2003a, p. 65), "encontramos como ya planteadas en el fondo de la existencia" y que pertenecen al horizonte total de sentido. Estas preguntas son abordadas a través de metáforas absolutas que suponen articulaciones metafísicas, cuya relevancia para la existencia cotidiana del hombre es lo que realmente interpela el pensar, según la indicación heideggeriana sobre la naturaleza de lo metafísico ${ }^{27}$. Aunque

25 Aquí Blumenberg retoma, siguiendo a Bröcker, la pregunta que mueve el itinerario de Heidegger desde Ser y tiempo hasta el apremiante juego de espejos de la simplicidad de la cuaternidad de tierra y cielo, divino y mortal, a saber, la pregunta por el mundo: "[q]ué sea propiamente el mundo -no lo que habitualmente se entiende por tal, sino el mundo auténtico, el verdadero, el entero, el sano, que en modo alguno se despliega ante la vista de todos, sino que está máximamente oculto, que quizá hoy no se da, ni se dio nunca, sino que es algo futuro- ésta es la pregunta que impele propiamente el pensar de Heidegger" (Blumenberg, 2003a, p. 64).

26 Nos referimos aquí al primer párrafo del prólogo a la Crítica de la razón pura en la edición de 1781, donde Kant afirma de manera clara: "[1] a razón humana tiene, en un género de sus conocimientos, el singular destino de verse agobiada por preguntas que no puede eludir, pues le son planteadas por la naturaleza de la razón misma, y que empero tampoco puede responder, pues sobrepasan toda facultad de la razón humana" (CRP A VII). El recorrido del proceder crítico es realmente una apropiación del sentido de esta situación.

27 En el famoso texto "El ser, un MacGuffin", publicado en 1997 en su obra póstuma La posibilidad de comprenderse, Blumenberg (2002) muestra de manera magistral la forma como el pensamiento se ve constantemente acosado por el suspenso provocado por cuestiones que no pueden ser disueltas apelando simplemente a que no tienen sentido porque no son verificables: "[ $n$ ]o hay leones en las Adirondack. Pero jay del viajero que dude de que en la maleta de su compañero de viaje hay un artilugio para cazar leones allí! A cambio de un conocimiento que no vale nada, ha vendido la intriga que debía ir creciendo durante las largas horas de viaje al mirar el enigmático equipaje. Si supiera desde el principio que la función pretendida está sustentada en el vacío, en el equipaje no habría ningún MacGuffin. El aburrimiento será el justo castigo para quien no quiera dejarse seducir por el 'suspense', igual que los preparativos para la expedición hacia la terra incognita de la comprensión del ser solo pueden provocar -o mejor: mantener- el bostezo aburrido de quien considera un sinsentido la pregunta por el sentido del ser" (Blumenberg, 2002, p. 127). Esta inquietud es justamente lo que da sentido a las preguntas metafísicas abriendo la posibilidad de soportar la vida gracias a la tensión propia de una trama de suspenso. 
Blumenberg utiliza rara vez la palabra "metafísica" en su sentido clásico, lo cierto es que las metáforas absolutas son caracterizadas, en la metaforología, como un medium de articulación metafísica por el cual se produce la referencia necesaria y aporética al horizonte total de sentido en la praxis cotidiana y en el discurso filosófico y científico. Es decir, como medium las metáforas absolutas articulan y proyectan la metafísica como disposición natural -la Naturanlage o metaphysica naturalis de la que hablaba antes Kant-.

Blumenberg caracteriza la situación universal del hombre por medio de la constelación aporética de ausencia de evidencia y exigencia de acción. Ciertamente, al hombre le faltan medios seguros para sostener una verdad, pero aun así está obligado a orientarse en las posibilidades infinitas que se le abren y a actuar según dichas orientaciones. Esta situación abre el camino de la retórica como una técnica en sentido estricto que permite que se disponga en lo provisional ${ }^{28}$ de verdades definitivas para poder obrar ante todo en asuntos morales (Blumenberg, 2001b, p. 411). Esta función de la retórica se muestra en particular en el rendimiento de la metáfora. Veamos cómo ocurre esto.

La referencia a la realidad humana es siempre indirecta, circunstancial, retrasada, selectiva y, ante todo, metafórica, pues con ello buscamos captar algo como algo, diferenciar de modo radical comportamientos distintos y comprender algo por medio de otra cosa. En este sentido, para mirar pasando de un objeto temático a otro, que se sospecha en previsión como revelador, "el rodeo metafórico acepta pues lo dado como lo desconocido, lo otro como lo familiar disponible a la mano" (Blumenberg, 2001b. p. 414). Dado que en las metáforas absolutas se busca hacer accesible lo desconocido por medio de expresiones de áreas familiares, ellas no crean verdades teóricas, pero cuando prevalecen pueden fundar instituciones y consensos de comprensión para la acción según orientaciones de sentido, permitiendo que el que las acepte pueda habitar en ellas, ya que en situaciones

28 En Paradigmas para una metaforología Blumenberg señala que en el estado final de la filosofía, donde domina en sentido estricto lo puramente conceptual, no hay lugar ya para el despliegue de la técnica del lenguaje traslaticio, pues ahora "todo puede definirse, así que todo tiene también que definirse, ya no queda nada lógicamente 'provisional', lo mismo que ha desaparecido la morale provisoire [moral provisional]. De ahora en adelante, todas las formas y elementos del modo traslaticio de hablar, en el más amplio sentido, resultarían provisionales y lógicamente superables; su único significado funcional sería el de ser pasos, el espíritu humano se adelantaría en ellos a su consumación responsable" (Blumenberg, 2003a, p. 42). 
concretas ofrecen motivos que impulsan a la acción. En efecto, el hombre necesita para su orientación en la vida respuestas a las preguntas por la constitución del mundo, por su esencia propia y por la vida. Para atender a dichas preguntas el teórico busca alcanzar la representación cataléptica de la esencia de la verdad.

Para cada orientación en la vida la pregunta decisiva podría ser la siguiente: ¿qué es propiamente el mundo en el cual se vive? En esta pregunta se indaga por aquello que sería lo decisivo en el comportamiento y en el proyecto de vida que se ha elegido. Examinemos este asunto a la luz de la siguiente indicación apócrifa de Jesús: "el mundo es un puente. Atraviésalo, pero no te quedes en él" (citado en Blumenberg, 2003a, p. 66). Como vemos, el mundo se comprende aquí como un lugar de paso (Durchgangsort) o, mejor, como un punto de cruce (Übergangsort) y la vida consistiría entonces en la preparación para el después del cruce. Ahora bien, la palabra de Jesús en la segunda frase señala las implicaciones pragmáticas de su metafórica absoluta, usada ya en la primera. Posteriormente, el mundo fue comparado también con una "tienda abierta", con un "hospital" o, como sucede en el caso del moralista francés Vauvenargues, con una organización o comportamiento social con determinadas reglas de juego: "quien haya visto las máscaras en un baile [...], puede hacerse la idea de la esencia del mundo" (citado en Blumenberg, 2003a, p. 67). Aquí el mundo aparece como un lugar de inautenticidad, pero esta metafórica del baile de máscaras (Maskenball) no despierta la esperanza de un después salvador, como ciertamente ocurre en la versión apócrifa de la sentencia de Jesús, aunque sí sugiere tener la cautela necesaria para tratar con todo lo que sucede en el mundo.

Como hemos indicado antes, Blumenberg señala la relevancia pragmática de la necesidad antropológica de las metáforas absolutas y, con ello, transforma la metaphysica naturalis de inspiración kantiana en una metaforología arqueológica que penetra en los elementos más básicos que configuran nuestra disposición natural a traspasar el límite del conocimiento con la construcción de conceptos. En este contexto, podemos decir que la verdad de las metáforas absolutas es pragmática, en un sentido amplio. Blumenberg (2003a) precisa este carácter de la siguiente manera:

Su contenido determina, como referencia orientativa, una conducta; dan estructura a un mundo; representan el siempre inexperimentable, inabarcable todo de la realidad [...]. Una pregunta como "qué es el mundo" no constituye 
desde luego el arranque de un discurso teórico. [...] Ese cuestionar cargado de implicaciones ha "agotado sus fuerzas" una y otra vez en metáforas, y de metáforas ha inducidos estilos de comportamiento en el mundo. La verdad de la metáfora es una vérite à faire-verdad por hacer-. (pp. 63-64)

En este sentido, la relevancia de la verdad pragmática de las metáforas absolutas, la verdad por hacer (vérite à faire), se basa en la necesidad práctica, pues el propio comportamiento se tendría que orientar en el horizonte de una totalidad comprensiva del sentido, del mundo, de la vida, de Dios. En efecto, con las metáforas absolutas no se determina nada con referencia a una presencia teórica dada; aunque ciertamente se articula con ello una perspectiva de sentido en la cual algo aparece como significativamente práctico para nosotros y, por esta razón, lo comprendemos de un modo pragmático, es decir, hacemos algo con él. De esta manera, Blumenberg resalta la relevancia pragmática de las metáforas absolutas, esto es, su sentido histórico-intersubjetivo.

La segunda dimensión de la metaforología blumenbergiana puede presentarse de la siguiente manera: la metáfora absoluta se hace legible como la cifra de la estructura fundamental de un mundo de vida histórico, pues indica "las certezas, las conjeturas, las valoraciones fundamentales y sustentadoras que regulan actitudes, expectativas, acciones y omisiones, aspiraciones e ilusiones, intereses e indiferencias de una época” (Blumenberg, 2003a, p. 63). Como podemos ver, Blumenberg entiende aquí las metáforas absolutas no como una mera producción histórica, sino como "fósiles guía [Leitfossilien]- de un sustrato arcaico" (Blumenberg, 1995, p. 98), en los cuales se hace legible la comprensión básica de los mundos de vida históricos y de las épocas. En este sentido, podemos decir que la metaforología blumenberguiana es el proyecto de una historiografía detectivesca. Cuando Blumenberg detecta una determinada metáfora absoluta como "fósil guía" de una época, la lee como un índice de estructuras arqueológicas profundas de un determinado mundo de la vida histórico.

Para ver cómo Blumenberg realiza este trabajo detectivesco, nos podemos detener ahora en su comprensión del mundo de la vida (Lebenswelt), pues se trata de un concepto fundamental para el despliegue de su programa metaforológico. Blumenberg (2013b,) caracteriza este concepto husserliano como un "concepto límite [Grenzbegriff] insuperable tanto en términos de universalidad como de 
trascendentalidad" (p. 39) ${ }^{29}$. Como tal el mundo de la vida no puede estar nunca presente, pues no se trata de algún objeto del cual podamos tener experiencia alguna para aprehenderlo categorialmente; está caracterizado, más bien, como la tendencia existente en cada mundo a ser sobreentendido, en la medida que configura lo que Husserl denomina "el universo de lo sobreentendido" (Blumenberg, 2013b, p. 87). Ya antes Husserl había descrito la subjetividad anónima del mundo de la vida como lo sobreentendido que presupone todo pensar, toda vitalidad en todos sus propósitos y rendimientos vitales. Siguiendo ahora la influencia de la antropología filosófica de Erich Rothacker ${ }^{30}$, Blumenberg modifica la concepción husserliana del a priori subjetivo del mundo de la vida convirtiéndola en un a prio$r i$ histórico del mundo de la vida. Su análisis remite a la estructura de autocomprensión del mundo de la vida, es decir, a "las certezas, las conjeturas, las valoraciones fundamentales y sustentadoras [...] de una época" (Blumenberg, 2003a, p. 63), ya que las metáforas absolutas indican y orientan como un a priori histórico el saber y la vida de un momento histórico determinado.

Estos sobreentendidos históricos no son invisibles para todos sus moradores contemporáneos, ya que por tener un "rol destacado" (Blumenberg, 2013b, p. 117) y carecer de fundamento son señalados a menudo como requiriendo una fundamentación expresa. Pero lo cierto es que solo se entienden justamente desde sí mismos. En este sentido, la misma inconciencia circunda al uso histórico de las metáforas absolutas, cuyo "valor de su testimonio tiene como presupuesto que el propio hablante no poseía ninguna metaforología, y ni siquiera podía

29 En su libro póstumo Teoría del mundo de la vida Blumenberg amplía la idea husserliana del límite a partir de los trabajos de Paul Du Bois-Reymond (Die allgemeine Functiontheorie. Metaphysik und Theorie der matematischen Grundbegriff: Größe, Grenze, Argument und Function). Incluso, en una nota a pie de página cita de manera expresa el sentido que le da Bois-Reymond al concepto límite: " [c] on el nombre de concepto límite se designa en la matemática un cierto procedimiento deductivo por el cual del tipo de secuencia de valores medibles u observables se deduce la existencia de valores que se sustraen por completo a la percepción y cuya presencia tampoco podrá ser demostrada jamás en sentido convencional” (Blumenberg, 2013b, p. 40).

30 El nombre de Erich Rothacker (1888-1965) se encuentra vinculado a los intentos de realizar una fundamentación filosófica de las ciencias del hombre, en particular, la de una antropología filosófica de la cultura, que pueda superar la separación habitual entre bios y logos. Para realizar esta empresa, Rothaker buscó entablar una relación mediata entre vida y espíritu como el soporte para desarrollar una historia del mundo de las culturas. Gracias a esta mediación, la investigación antropológica descubrió el enorme potencial de simbolización en el cual los fenómenos humanos encuentran su expresión (Tremmel, 2013, pp. 243-244). 
poseerla" (Blumenberg, 2003a, p. 62) 31. Así pues, el valor de fósil indicativo de las metáforas muestra que ellas no son seleccionadas de modo consciente, pues parece, más bien, que resultan de una conformidad inconsciente con las estructuras más básicas del mundo de la vida, es decir, siguen la lógica de los fenómenos históricos. Para Blumenberg, las metáforas absolutas no son una mera indicación etérea de estructuras arqueológicas de lo sobreentendido de un mundo de la vida histórico, pues son, en efecto, la realización de dichas estructuras. Es decir, no son sobreentendidos de cualquier tipo, sino que indican las aceptaciones metafísicas fundamentales de un mundo de la vida histórico que se muestra a través de ellas. Como lo indicamos al inicio del presente trabajo, las metáforas absolutas son entonces la forma más destacada del lenguaje de la metafísica. Por esta razón, Blumenberg las usa para aproximarse a los sobreentendidos metafísicos que expresan el a priori histórico de una época determinada. Con esto nos topamos aquí con la segunda dimensión de la metaforología: ser una arqueología de las estructuras metafísicas fundamentales de un determinado mundo de la vida histórico ${ }^{32}$. ¿Cómo podemos entender aquí este viraje histórico-arqueológico?

\section{El despliegue histórico de una disposición natural}

A Diferencia de Derrida, Blumenberg señala la interconexión y la pluralidad de las metáforas. Mientras que Derrida (2010, p. 28) suele hablar de manera explícita de la red ontológico-histórica de los conceptos fundadores o tropos, la tendencia de Blumenberg consiste en perseguir en la historia la transformación diacrónica de una determinada metáfora absoluta, por ejemplo, la historia de la metafórica de la verdad (Blumenberg, 2003a, pp. 49-125) o la historia de la

31 La cursiva es mía. Aquí es necesario tener en cuenta que la metaforología no pretende encontrar en las metáforas la respuesta a las preguntas que la razón teórica no ha podido contestar; su intención es más humilde, pues simplemente busca indicar lo que hacemos con la apelación a las metáforas que están encarnadas en dichas preguntas. En este sentido, se debe entender la transformación de la metaphysica naturalis kantiana en la metaforología como un cierto retorno arqueológico a los elementos más básicos de nuestro trato con el mundo (Blumenberg, 2003a, p. 62).

32 La indicación de este viraje arqueológico se puede ver cuando Blumenberg (1995) señala que "la metáfora reclama una originalidad en la que están arraigadas no solo los ámbitos privados y ociosos de nuestra experiencia, los mundos de los paseantes o de los poetas, sino también los aspectos elaborados y extrañados en la jerga especializada de la posición teórica” (p. 100). 
metafórica náutica de la existencia (Blumenberg, 1995, p. 39)33, modifica esta interconexión de las metáforas indicada por Derrida. Si en las metáforas absolutas se muestra lo sobreentendido de un mundo de la vida histórico, teniendo en cuenta los objetos metafísicos centrales o teológicos, tales como el mundo, la verdad, Dios, se puede esperar entonces que las metáforas particulares se relacionen mutuamente, es decir, que las metáforas ontológicas, teológicas y antropológicas se sintonicen unas con otras, pero no de modo secuencial. Por esta razón, podemos decir pues que "los fósiles guía" metafóricos de una época histórica expresan una formación arqueológica coherente, esto es, una estructura sistemática que puede ser puesta al descubierto en el trabajo metaforológico. En este sentido, los paradigmas metaforológicos presentes en una determinada red histórica de metáforas absolutas forman la estructura profunda de una época histórica y, por tanto, son realización efectiva del Weltbegriff de la filosofía del que hablaba Kant antes en la Crítica de la razón pura.

Para la caracterización de los fenómenos históricos, objeto de su consideración, Blumenberg se concentra en una metáfora absoluta, cuya historia narrativa investiga de manera asidua, pues la considera como un arquetipo secreto, esto es, cubierto bajo la influencia de estructuras sistemáticas circundantes. No obstante, los esfuerzos históricos de Blumenberg se topan con una serie de dificultades al momento de querer examinar el fondo de una transformación histórica dada; por ejemplo, determinar el momento originario de su configuración o el curso y variaciones de su narrativa en la historia. Para encarar estas dificultades, Blumenberg propone el modelo fascinante de una metacinética (Metakinetik) de los horizontes históricos de sentido. Esta metacinética enmarca la realización efectiva del proyecto de una metaforología más allá de su bosquejo propedéutico inicial, de la misma

33 Al inicio de Naufragio con espectador Blumenberg (1995) caracteriza la presentación de la metafórica náutica de la existencia de la siguiente manera: "[e]l hombre conduce su vida y levanta sus instituciones sobre tierra firme. Sin embargo, prefiere concebir el movimiento de su existencia, en su conjunto, mediante la metafórica de la navegación arriesgada. El repertorio de esta metafórica náutica de la existencia es proteico. Hay costas e islas, puertos y alta mar, arrecifes y tormentas, profundidades y bonanzas, velas y timones, timoneles y tenederos, brújula y navegación astronómica, faros y pilotos. A menudo, la representación de los peligros de alta mar sólo sirve para resaltar la comodidad y la calma, la seguridad y serenidad del puerto en el que ha de concluir la travesía" (p. 13). El alcance temático y metodológico de esta metafórica náutica para la comprensión de nuestra situación histórica ha sido abordado ampliamente en los trabajos recientes de Enver Torregroza (2014a; 2014b). 
manera que en Kant la crítica de la razón teórica delimita el campo de despliegue posible de la metafísica como disposición natural de la razón humana en cuanto debe realizarse de manera cósmica, esto es, en el mundo moral que se abre a partir del canon. Es decir, la tarea del proyecto de una metaforología encuentra su propio límite cuando se topa justamente con la exigencia de una investigación más profunda aún pendiente $e^{34}$. Así pues, el discurso de una "metacinética de los horizontes históricos de sentido y de las formas de mirar" (Blumenberg, 2003a, p. 47) muestra que el a priori histórico de los sobreentendidos mundo-vitales se realiza realmente bajo la forma de la estructura sistemática de la metáfora absoluta que se modifica en una permanente transformación metacinética.

Dado que las metáforas absolutas forman el pensar y obrar de una época histórica determinada, la sustitución de una metáfora por otra es, por tanto, una acción consecuente, porque solo así las orientaciones fundamentales de un horizonte histórico de sentido se ponen en movimiento en una trama mundo-vital determinada. Por esta razón, podemos asumir la estructura de las metáforas absolutas como constituyendo un sistema tópico de lugares (Stelle) y, en este sentido, se puede describir también su metacinética como un permanente cambio de reparto de papeles (Umbesetzung) al interior de este sistema de lugares ${ }^{35}$. Blumenberg introduce el concepto de Umbesetzung en relación con su discusión sobre el problema del concepto de época histórica, es decir, en el contexto en el cual

34 Este límite propio de la metaforología es señalado por Blumenberg (2003a) con los siguientes términos: "[s]e propone delimitar campos en los que se pueden conjeturar metáforas absolutas, y poner a prueba criterios para su fijación. Que se dé a esas metáforas el nombre de absolutas solo significa que muestran su resistencia a la pretensión terminológica, que no se pueden resolver en conceptualidad, no que una metáfora no pueda ser sustituida o reemplazada por otra, o bien corregida por otra más precisa. De ahí que también las metáforas absolutas tengan historia. Tienen historia en un sentido más radical que los conceptos, pues el cambio histórico de una metáfora pone en primer plano la metacinética de los horizontes históricos de sentido y de las formas de mirar en cuyo interior experimentan los conceptos sus modificaciones" (p. 47. Cursivas mías).

35 Según Müller, Blumenberg desarrolla el programa metódico del cambio de reparto de papeles (Umbesetzung) a partir de la diferencia entre el concepto de sustancia y el de función, para resaltar de este modo su transformación radical de la antropología filosófica. En la Legitimidad de la edad moderna Blumenberg introduce la noción de Umbesetzung en su autolimitación secular, apartándose así de las formas teológicas habituales de la Umsetzung (conversión). En este contexto, Blumenberg señala que la función está antes que el contenido. Esto resulta particularmente revelador, cuando se mira en su conjunto la dinámica histórica de la Modernidad, donde se produce una "Umbesetzung funcional sin continuidad de contenidos. Este es el núcleo del modelo de función de la historia” (Müller, 2005, p. 219). 
se asume la dificultad de comprender los cambios de reparto metacinéticos fundamentales en una descripción historiográfica ${ }^{36}$. Porque, efectivamente, "no hay testigos de los cambios radicales de época” (Blumenberg, 2008, p. 467), el concepto de época es entonces una categoría de descripción ulterior, esto es, un " $\mathrm{Li}$ mes inadvertido [ein unmerklicher Limes], no vinculado a ningún dato o acontecimiento pregnante" (Blumenberg, 2008, p. 467). Por esta razón, el problema de la época, la pregunta por la posibilidad de la experiencia, está aquí enrollado en su propia posibilidad. Es decir,

todas las modificaciones, todos los cambios de lo antiguo a lo nuevo solo nos son accesibles si pueden ser relacionados con un marco de referencia constante [...]. El concepto de cambio de reparto de papeles [Umbesetzung] implica un mínimo de identidad [Identität] que tiene que poder ser encontrado -0 , al menos supuesto y buscado- incluso en el movimiento más agitado de la historia. (Blumenberg, 2008, pp. 463-464)

Ahora bien, este "mínimo de identidad" radica en que el cambio de reparto de papeles podría comprender la nueva ocupación del lugar como "respuestas a preguntas que son iguales" (Blumenberg, 2008, p. 467) ${ }^{37}$.

36 Un ejemplo de este uso se puede encontrar en el capítulo dedicado al análisis de las etapas del concepto de época en la Legitimación de la edad moderna (Blumenberg, 2008, pp. 455-477). Discutiendo el sentido de la autocomprensión moderna al interior del romanticismo, Blumenberg señala que "el problema de la época ha de ser planteado a partir de la cuestión sobre la posibilidad de tener una experiencia de la misma. Todas las modificaciones, todos los cambios de lo antiguo a lo nuevo solo nos son accesibles si pueden ser relacionados con un marco de referencia constante -en vez de la 'sustancia' de la que habla Kant-, mediante el cual pueden ser definidos los requisitos que han de ser satisfechos tratándose del mismo lugar [Stelle]. [...] En el caso de que los sistemas sean producto, según dice Goethe, de una 'visión sobre el mundo y el hombre', el mentado cambio de reparto de papeles significaría que los diferentes enunciados pueden ser entendidos como respuestas a preguntas que son iguales" (Blumenberg, 2008, pp. 463-464). En este sentido, podemos decir que el retorno a las viejas preguntas de la metafísica, que Kant caracteriza como el volver a una vieja amada con la cual se ha tenido una desavenencia (CRP A 850) es realmente expresión de la dinámica metacinética que se pone en movimiento en el cambio de reparto de papeles que envuelven a las metáforas absolutas que han configurado en su historia a la metafísica occidental. Esta metacinética se puede describir también como una novela, esto es, como una determinada forma renovada de Bildungsroman, donde los personajes mutan constantemente según el desarrollo de la trama vital.

37 Para Blumenberg, tanto los acontecimientos de la historia como sus sistemas de comprensión se basan en estructuras dialogales, de modo que, por ejemplo, la Modernidad no radica en el mero despliegue histórico del monólogo de un sujeto absoluto que busca en todo momento autoafirmarse, como de alguna manera lo presupone el movimiento fenomenológico del espíritu 
Blumenberg (2008, p. 380) ve en el subsuelo de las metáforas absolutas la habitual lógica de la pregunta-respuesta, es decir, una estructura dialógica. La nueva metáfora presupone así las posiciones sintácticas de viejos paradigmas, en la medida que los asume y resuelve ${ }^{38}$. En este sentido, las metáforas absolutas "responden a preguntas aparentemente ingenuas, incontestables por principio, cuya relevancia radica simplemente en que no son eliminables, porque nosotros no las planteamos, sino que nos las encontramos en el fondo de la existencia" (Blumenberg, 2003, p. 62). Las metáforas absolutas serían respuestas mundovitales e históricamente cambiantes a preguntas fundamentales que se resisten a mantenerse como idénticas en su formulación, esto es, a preguntas metafísicas que, como lo señala Kant, regresaremos siempre a ellas como a una amada con la cual se ha tenido una desavenencia.

Al contrario de la consideración según la cual las metáforas cambiantes responden a preguntas que permanecen iguales y que como tales pueden todavía ser fundadas apelando a una unidad originaria estática, Rüdiger Campe (2009, p. 287) concibe la compleja acuñación de preguntas y respuestas como una modificación constante de múltiples interacciones textuales. En estos procesos intertextuales altamente complejos, que son los objetos de las historias de la técnica de dar una respuesta a la pregunta las preguntas devienen respuestas; las metáforas, conceptos. En esta lectura la concepción jerárquica de la metacinética y de su lógica de respuestas y preguntas se remite a una estructura plana e interdependiente del todo que se determina de manera textual. Si aceptamos esta perspectiva

según Hegel, sino en "el conjunto de esfuerzos sistemáticos por contestar, dentro de un nuevo contexto, a las preguntas que le habían sido planteadas al hombre en la Edad Media. [...] Todo acontecimiento, en el sentido más amplio del término, encierra una correspondencia, replica a una pregunta, responde a un desafío o a un malestar, salva alguna inconsistencia, desencadena una tensión u ocupa un sitio que había quedado vacío" (Blumenberg, 2008, pp. 380-381). Esta estructura dialogal es omitida en la tesis heideggeriana de la historia del ser, según la cual el decurso histórico que va de la Antigüedad griega a la Modernidad está determinado por una misma y única cuestión, a saber, la pregunta que interroga por el ser del ente y en dicha pregunta el ser mismo ha quedado en el olvido.

38 Este proceso de constante recepción y resolución se basa en un hecho antropológico fundamental que Blumenberg (2002) llama la delegación: "[s]ustituibles lo somos todos por necesidad, insustituible quiere serlo cada uno. De esta fractura en la existencia surge la tercera idea: la de la representabilidad. El insustituible no tiene por qué hacer él mismo aquello para lo que está; puede traspasar el mando, y por la acción de delegar hacer, también en lo que toca a otros, como si fuera él mismo quien lo hace" (p. 137). 
interpretativa de Campe, las preguntas no podrían ser pensadas como previamente encontradas, como ciertamente lo sugiere Blumenberg, sino tan solo como emergiendo de viejos archivos discursivos. Aún más, se debería pensar en una cierta retroalimentación directa entre las preguntas y las respuestas. Pero no debemos olvidar aquí que la respuesta a una pregunta implica ya la formulación de una determinada pregunta de enlace y una expectativa de respuesta que no podría aparecer en cualquier otra respuesta. Si se acepta la exigencia de apelar a una unidad originaria dada, esto conduciría finalmente a que no surgiría en un momento dado nuevas preguntas, pues ya se habría encontrado una única respuesta definitiva. No olvidemos empero que la historia de la metacinética que caracteriza a las metáforas absolutas despliega la dinámica histórica de una constante génesis abierta de formas lingüísticas y de enunciados con sentido. Por esta razón, consideramos que en la metaforología Blumenberg busca realmente relacionar la historia de los conceptos y el proceder arqueológico de su metaforología ${ }^{39}$.

En 1967 Blumenberg señala que él se vinculó con el proyecto de la historia de los conceptos de Ritter debido a un interés teórico que buscaba incrementar lo puramente histórico, a saber, captar algo así como la "estructura de la génesis de los conceptos" (Blumenberg, 1967, p. 79). Y en 1971, con motivo de la aparición del primer tomo del Historische Wörterbuch der Philosophie, Blumenberg enmarca la metaforología en esta perspectiva de trabajo ${ }^{40}$. Siguiendo entonces su interés por la "lógica interna de la constitución de los conceptos" (Blumenberg, 1967, p. 79), Blumenberg acentúa dos dimensiones fundamentales en la configuración de dicha historia: para la investigación histórico-conceptual sería importante, por un lado, comprender y practicar críticamente las formaciones del concepto como operaciones con consecuencias, y, por el otro, cultivar los órganos para "el diagnóstico de problemas que todavía se queman lentamente bajo la

39 En este punto se hace necesario recordar que Blumenberg (1967, p. 79) formuló de manera incipiente la necesidad de esta relación en su texto de 1967, publicado en el Jahrbuch der Akademie der Wissenschaften und Literatur Mainz.

40 Esta decisión lleva a Blumenberg (1971) a considerar que, "más bien, la metaforología ofrece a la historia de los conceptos una ayuda para introducirse en la estructura genética de la formación del concepto, en la cual ciertamente no se cumple la exigencia de la univocidad, pero permite reconocer la univocidad del resultado como el empobrecimiento en el fondo imaginativo y en las orientaciones mundo-vitales" (p. 163). 
superficie de áreas que aparecen teniendo una sede terminológica" (Blumenberg, 1967, p. 80). Estas dos formulaciones abren, sin duda, perspectivas complejas de investigación, las cuales el desarrollo programático de la metaforología intentará posteriormente abordar.

Comprender la formación de los conceptos como "operaciones con consecuencias [Vorgänge mit Folgen]" recuerda una teoría implícita de la estructura de la génesis de los conceptos, a saber, aquella que dice que los conceptos nacen en relaciones sistemáticas, en discursos con cuestiones problemáticas específicas, a partir de determinadas perspectivas y, por tanto, a través de formas diversas de manejo teórico-práctico con objetos, por ejemplo, en el espacio del trabajo. Esto quiere que los conceptos se configuran en dominios formados por intereses que actúan por fuera de lo discursivo. Los conceptos se fundan además en las latencias lingüísticas de usos anteriores. Desde estas restricciones intra y extradiscursivas los conceptos surgen configurando nuevos espacios para su comprensión y aplicación. En su estructura intensional y extensional, los conceptos son realmente consecuencias. En este sentido, los conceptos entran en el dominio sistemático y, de este modo, abren posibilidades de consecuencias y encierran otros conceptos futuros. Por lo tanto, comprender las formaciones de determinados conceptos como operaciones con y a partir de consecuencias resalta una lógica histórica de consecuencias micrológicas de constitución interna, que demanda la consideración detallada de las condiciones intra y extradiscursivas que dan nacimiento a los conceptos ${ }^{41}$.

Por esta razón, Blumenberg señala que la historia de los conceptos demanda tener en cuenta las profundas estructuras metafísicas mundo-vitales que expresan las metáforas absolutas. En su ensayo sobre la luz Blumenberg describe, por ejemplo, la relación entre la metafórica y la conceptualidad de la siguiente manera:

41 Como un elemento determinante de las condiciones extradiscursivas que enmarcan la génesis de un concepto dado podemos señalar el lugar de las anécdotas. En el origen de un concepto podemos encontrar también situaciones de carácter anecdótico que determinan su despliegue y posterior comprensión. Para Blumenberg, la anécdota es uno de los elementos centrales de su teoría de la inconceptualidad (Zill, 2014, p. 26). En este sentido, la adecuada comprensión de la historia de un concepto implica realizar la novela que lo enmarca, pues toda historia es comprensible solo en su validez narrativa (Renn, 1999, p. 319). 
esta avanzada del concepto es en su condición de agregado plástica, sensible para lo implícito y como tal está poco controlada por las formas fijas de la tradición. Aquí se ha obtenido con frecuencia la expresión de lo que en la arquitectónica fija del sistema no ha encontrado medio para expresarse. (Blumenberg, 2001a, p. 139)

Como vemos, la metafórica de las expresiones "formas fijas de la tradición", “arquitectónica fija”, la de lo "plástico" y lo completamente "sensible” señalan con claridad que Blumenberg le da a la metáfora una inmediatez irreductible, a saber, la vitalidad de la expresión.

Para comprender el sentido de esta vitalidad, podemos retomar la idea kantiana de la metafísica como Naturanlage, pero asumida ahora como historia de la técnica propia de la metáfora. Como hemos indicado antes, la metaforología quiere desplegar una cierta concepción jerárquica de la metáfora como arqueología de la conceptualidad. No podemos olvidar empero que si las metáforas tienen consecuencias en los conceptos, se puede aceptar también que es posible el efecto opuesto. Las metáforas deben, por tanto, encajar en los sistemas conceptuales en los que son usadas. En este sentido, se puede decir que los conceptos nacen no solo en el horizonte de las metáforas absolutas, pues tienen también una influencia para usar una determinada metáfora en un discurso histórico. Es decir, podemos reemplazar así la estructura jerárquica de la arqueología por una lógica discursiva de interdependencia. Esta interdependencia se puede describir del siguiente modo: la lógica de la recepción, restringida inicialmente por Blumenberg a la de la conceptualidad, se convierte ahora en una cierta lógica discursiva que comprende tanto el movimiento de la conceptualidad como el de su metafórica. Así pues, la descripción de la historia de la técnica que está a la base de la metáfora implica la reconstrucción analítico-discursiva del decurso de sus consecuencias históricas, ya que de este modo se muestra la conexión entre la metaforología y la historia de los conceptos. Siguiendo este vínculo, podemos decir que las afirmaciones histórico-vitales regulan el acontecimiento del cambio de reparto de papeles.

De este modo, la historia de este proceder técnico conduce a una revaloración de la relación entre técnica y mundo de la vida. Estos conceptos provienen, obviamente, de Husserl y están normalmente relacionados en términos de oposición. Para Husserl, el fundamento de la crisis de las ciencias occidentales radica en que, a través de la primacía del método y de la formalización, el proceder 
técnico se erige en las matemáticas como única forma posible de proceder racional; con esto se encubre la adecuada referencia originaria de este procedimiento al contexto del mundo de la vida. Según Blumenberg (1981), el proceder técnico significa para Husserl "un fenómeno patológico" (p. 40). Por esta razón, él se aparta de la interpretación husserliana de la relación estrecha entre técnica y patología, pues para Blumenberg (1981) la "conexión entre mundo de la vida y técnica es más complicada que como la vio Husserl” (p. 37). En efecto, el proceso de tecnificación no es simplemente el opuesto del mundo de la vida, ya que sus productos entran en las estructuras de autocomprensión del mundo de la vida del hombre ${ }^{42}$. Por esta razón, los productos teóricos, las metáforas u otras expresiones, que más o menos llevan consigo implicaciones teóricas, se convierten así en una parte estructural de las autocomprensiones de un mundo de la vida histórico y comienzan a regular dicho mundo. Es decir, las autocomprensiones regulativas de un mundo de la vida histórico son productos técnicos o teóricos.

Podemos afirmar entonces que el proceso de tecnificación es realmente un acontecimiento que tiene lugar en el mundo de la vida del hombre y solo en él. Como otras formas lingüísticas, las metáforas son "un producto semifacturado [Halbzeug]" (Blumenberg, 2003a, p. 85). La palabra Halbzeug es un término técnico proveniente de la administración industrial y económica ${ }^{43}$, que señala

42 En este contexto, Blumenberg (2013b) considera que "decir que el mundo de la vida está libre de teoría y es anterior a la teoría no significa en modo alguno que en las concepciones y opiniones, en suma, en la visión del mundo de este mundo de la vida, no haya sedimentos de experiencias y conocimientos, que por su tipo pueden ser similares a los resultados teóricos o incluso algunas vez fueron resultados de esa índole, por ejemplo, en el transporte de elementos astronómicos y astrológicos de Babilonia o Egipto a la Grecia presocrática" (p. 88).

43 Con esta palabra se designa aquellos productos intermedios que se presentan en los primeros pasos de fabricación de un producto terminado. Son entonces los productos resultantes de la transformación de la materia prima en piezas de trabajo, por ejemplo, las hojas, las varillas, los tubos, las placas y las bobinas. La fabricación de estos productos es algo común en la industria metalmecánica. La variedad de estos productos es muy grande, pues se debe atender a una gran diversidad de especificaciones del material y de sus condiciones de calidad, según los requerimientos de la elaboración de productos finales. Estos productos semimanufacturados se pueden incorporar posteriormente a la cadena productiva, cuando se funden o se modelan en productos terminados, ya sea para entrar después en la cadena comercial o para ser integrados en procesos de producción más complejos. En general, no se toman como productos semifacturados a los gránulos, polvos, líquidos o gases, ya que estos productos, a diferencia de los productos semiacabados, no son definidos geométricamente, es decir, no son cuerpos sólidos y, por lo tanto, no cumplen la condición de estar a medio terminar. Los bloques terminados o módulos tampoco se incluyen en 
niveles intermedios de productos industriales entre la materia prima y los productos terminados. En este contexto, podemos decir que las metáforas no son simplemente algo vivo o puramente sensible, sino que tienen un carácter de producto semifacturado. Por tanto, las metáforas, los conceptos y las formas lingüísticas son en general un producto histórico espiritual semifacturado que nace según lógicas discursivas y de acuerdo con la historia de su recepción, permitiendo a su vez una reconstrucción histórica de su procedimiento técnico.

Ahora bien, las descripciones históricas y filosóficas de Blumenberg se caracterizan por tener una inmanencia sistemática que permite mostrar las implicaciones de su metaforología y de la historia de su técnica. Recordemos que, según la teoría general de la recepción, cada nuevo desarrollo se hace plausible desde lo anterior. De esta manera, Blumenberg muestra su tesis fundamental sobre el devenir histórico de lo nuevo, según la cual "lo nuevo en la historia no puede ser cualquier cosa, sino que está sujeto al rigor de un conjunto de expectativas y necesidades ya dadas de antemano" (Blumenberg, 2008, p. 464).

Esta lógica inmanente se muestra bajo las metáforas historiográficas de la pseudomorfosis ${ }^{44}$. La pseudomorfosis describe el decurso histórico-técnico del cambio de reparto de papeles (Umbesetzung). Es decir, lo nuevo en la historia no irrumpe tan solo de modo independiente, sino que se forma mientras se reemplaza lentamente lo viejo concluido o modificado por el desgaste o pseudomorfosis. Así pues, lo nuevo es un producto semifacturado (Halbzeng), que emerge de una lógica de efectos históricos provenientes de formas antiguas en cuyo lugar irrumpe reemplazando lo antiguo y, por tanto, corresponde a requerimientos sistemáticos unidos a un lugar determinado y posición.

esta categoría, ya que son ampliamente utilizados en el diseño original y, por lo tanto, -al menos en términos de procesamiento de materiales- son considerados una especie de productos finales, aunque en apariencia puedan ser vinculados a una nueva cadena de producción de un objeto posterior a terminar. Los productos semifacturados ofrecen un material semiacabado; por esta razón, obedecen a procesos de producción planificada y rentable. No son entonces meros residuos en la cadena de producción (Creutzig, 2009, p. 75).

44 La pseudomorfosis es un concepto técnico proveniente de la mineralogía. Se refiere a la existencia de un mineral con la forma cristalina externa de otra especie de mineral. "Si el cristal de un mineral dado se altera de forma que la estructura interna o la composición química cambien, pero la forma externa prevalezca, se dice que se ha formado una pseudomorfosis (del griego falsa forma). La estructura y composición química de un mineral pseudomorfo pertenece a una especie mineral, aunque la forma del cristal corresponda a otra” (Klein, 2006, p. 176). 
Teniendo esto en cuenta, Blumenberg emprende una crítica radical a la interpretación heideggeriana de la Modernidad ${ }^{45}$. En el segundo Heidegger el fundamento histórico ontológico de una época histórica, esto es, la posición metafísica básica que determina la experiencia del mundo, procede del claro (Lichtung) o del destino de una instancia anónima, el ser. En este sentido, la historia sería entonces historia del ser (Seinsgeschichte). En la concepción de una historia discontinua de la historia del ser las épocas históricas no se relacionan unas con otras según la lógica de la sucesión; más bien, cada una entabla una relación con el ser como el origen de una estructura metafísica fundamental. Blumenberg (2008, p. 381) critica esta discontinuidad de épocas a partir de su relación sistemático-histórica, en la cual cada época se constituye sistemáticamente como respuesta a un desafío que ante todo permanece siempre abierto.

Esta articulación histórica de preguntas y respuestas tiene para Blumenberg una dimensión dramática, que como tal puede ser reconstruida como una narración que refleja en la palabra la trama interna de situaciones, personajes, contextos de significación y momentos históricos dados ${ }^{46}$, en los que normalmente se

45 En la Legitimación de la Edad Moderna esta crítica Blumenberg (2008) la presenta en los siguientes términos: "La Edad Moderna como episodio de la historia del ser -y, más especialmente, del abandono del ser- tendría impresos en sí misma los estigmas de la dominación, de la servidumbre de la teoría respecto a la tecnicidad, de la autorreproducción del hombre no precisamente como respuestas a un reto, el que sea, que se le ha dejado en herencia, sino como una de todas esas perplejidades sin tregua en torno a aquel ser oculto, retirado desde los tiempos de los presocráticos [...] No son los contenidos de la época los que se convierten en una pseudomorfosis de su origen teológico, sino que la cualificación de su lugar en la historia sólo es determinable como una pseudoteología" (p. 193. Las cursivas son del original).

46 Para Blumenberg, todo descubrimiento conceptual lleva implícito una anécdota o una historia vital que lo enmarca y determina en su desarrollo. Por ejemplo, refiriéndose a su pasión por la historia de los conceptos, recuerda la gran afición de su padre por la fotografía: "[1]o que me fascinaba era el proceso de cómo algo surgía de la nada, algo que antes no existía en absoluto. Las explicaciones paternas acerca de química privada -que había abandonado el bachillerato a mitad y nunca había vuelto, ya que se dedicó al comercio de libros-, aquellas invitaciones a la alquimia, apenas añadían nada. Así se desarrolló el primer artículo de mi credo: lo veía ante mí, cómo fue la creación del mundo. Primero nada y luego algo -y algo solo porque antes se había procurado la luz-. El procedimiento bíblico me parecía, desde el punto de vista fototécnico, completamente correcto y la cámara oscura una imitación de la situación general del universo antes del primer día de la creación. Sin que se hiciera la oscuridad, nada podía surgir de la nada y la luz era la condición más importante de lo que se llamaba una correcta exposición. Entre mis manos, agitando con cuidado las placas en los baños, surgía el mundo -sin tanta contundencia ni jaleo, por supuesto, como en el preludio bíblico, pero en principio con el mismo procedimiento-. No me perdonarán: uno que no cree en la creación entiende perfectamente su concepto, tal como se le 
desenvuelve el mundo de la vida del hombre. En este sentido, podemos decir que si la metafísica es realmente el retorno a una amada con la cual se ha tenido una desavenencia, su historia puede ser muy bien narrada como la de una aventura. Dentro de las narraciones de aventura un lugar muy especial lo ocupan las aventuras amorosas. En ellas descubrimos no solo las oscilaciones más íntimas del corazón, sino ante todo las configuraciones mundo-vitales que enmarcan estos vaivenes intensos, pues en ellas los participantes en la trama quieren dar un lugar a eso nuevo que los conmueve. Para quien no está inmerso en la trama, esto nuevo puede ser tomado como un disparate o como un mero efecto del destino. La aventura amorosa no sigue empero la lógica cerrada del destino, sino aquella que Jankélévitch (1989, p. 18) denomina con la palabra francesa destinée ${ }^{47}$, indicando así el modo como el hombre modifica su propia suerte. Esta modificación señala justamente lo que hemos querido indicar aquí con la función del cambio del reparto de papeles que caracteriza a todo movimiento metaforológico. En efecto, todo comienza con un simple juego y en la medida que se incrementa la tensión, los participantes en la trama se precipitan como los átomos de Epicuro: se produce"una reacción en cadena y nacen las elevaciones, las cordilleras, los continentes, todo el relieve del suelo y, en una palabra, el mundo variopinto que habitamos" (Jankélévitch, 1989, p. 36). Como vemos, el "clinamen”48 de este

'producía' visiblemente en la cámara oscura. Desde entonces tuve al menos una idea de cómo nacen los conceptos" (Blumenberg, 2003b, pp. 27-28).

47 Para mostrar el carácter abierto de la destinée frente a lo cerrado del destino, Jankélévitch (1989) recurre a la presentación de las historias vitales de Rimbaud y Gauguin: "[h] acer contrabando de armas en Abisinia y morir luego miserablemente en un lazareto de Marsella no formaba parte del destino de un poeta. Y, como todo el mundo sabe, esa fue la suerte de Rimbaud. ¿Acaso no era ese el destino de un poeta, pero sí su destinée? Publicar volúmenes de versos en editoriales parisinas, ganar o dejar de ganar tal premio, pronunciar oráculos en las revistas y desempeñar su papel en el teatro de marionetas de la república de las letras forma parte del destino de un poeta. En cambio, esa actividad disparatada, extraña y peregrina que consiste en vender armas a los reyes de Arabia no está prevista en la carrera de un escritor. Y, sin embargo, esa fue la destinée de Rimbaud. No formaba parte del destino de un pintor vivir en Tahití, casarse con una mujer maorí y acabar muriendo en una miserable choza de Oceanía. El destino de un pintor es vivir en París, frecuentar galerías, vender o no sus lienzos y tener, como todo el mundo, una masía en Provenza. Lo que no formaba parte del destino de Gauguin, sin duda formaba parte, en un sentido más profundo, de su destinée" (pp. 30-31).

48 En De rerum natura Lucrecio desarrolla la teoría epicúrea del clinamen como la desviación espontánea de la trayectoria de un átomo como origen de una nueva serie causal, para resolver de este modo el viejo problema de la mecánica aristotélica de la regresión al infinito de las cadenas 
encuentro de los amantes tiene consecuencias mundo-vitales, es decir, todo un nuevo mundo se erige en él.

Toda aventura lleva consigo grandes peligros tanto en el proceso de su ejecución como en lo conseguido en ella. La aventura amorosa, obviamente, no es una excepción. Su peligro consiste en cerrar lo abierto de la destinée. Por ejemplo, en medio de la monotonía de la vida burguesa, un buen día un hombre tropieza de repente con la sonrisa de una muchacha y pronto inicia los avatares propios de la aventura amorosa: su rutina diaria cambia y comienza a frecuentar lugares que antes no se había imaginado visitar. A causa de los rodeos por la ciudad comienza a llegar tarde a su trabajo y ya no cumple a cabalidad con los compromisos laborales y familiares que antes lo acosaban. Debido a sus reiterados incumplimientos pierde su puesto de trabajo y con ello también la seguridad y estabilidad de su antiguo hogar. Sin embargo, nuestro hombre se siente liberado para entregarse así, sin límite alguno, a lo que se abre en su aventura: una nueva vida al lado de la muchacha que una vez le sonrió en medio de la soledad de una gran ciudad. Su deseo de consolidar la felicidad que ahora experimenta, gracias a los riesgos de su aventura, va creciendo con el paso del tiempo y siente también que tiene que darle un lugar a esta alegría en su mundo, pues solo así realizaría lo que antes tanto anhelaba: levantar un lugar lleno de amor e intensidad plena. Los constantes rodeos de su aventura y la persistencia de ser fiel al clinamen conducen al hombre a comprometerse o legalizar su nueva situación, pero con ello la intensidad de lo gestado en la aventura disminuye también, "porque cuando la aventura acaba en boda el comienzo incesante se extingue en las arenas de la continuación” (Jankélévitch, 1989, p. 37). En esta situación se revela justamente la tensión que

causales del movimiento, sin tener que apelar a la acción de un Dios ordenador que funcione como primer motor inmóvil. De esta manera, se introduce al interior del movimiento mecánico un factor de indeterminación en la serie causal que, no obstante, es fuente de efectos reales en el mundo. Gracias a esta teoría epicúrea del clinamen se inicia la justificación ontológica del libre albedrio. Para Deleuze (1988), el clinamen "no es en modo alguno un cambio de dirección en el movimiento del átomo, y mucho menos una indeterminación que dé fe de una libertad de tipo físico. Es la determinación original del movimiento, la síntesis del movimiento y de su dirección, al relacionar a un átomo con otro. Incerto tempore no quiere decir indeterminado, sino inasignable, ilocalizable. Si es cierto que el átomo, elemento del pensamiento, se mueve 'tan de prisa como el pensamiento mismo', según Epicuro dice en su carta a Herodoto, el clinamen, entonces, es la determinación recíproca que se produce 'en un tiempo más pequeño que el mínimo de tiempo continuo pensable' (pp. 302-303). 
atraviesa a la aventura amorosa: lo abierto en el clinamen tiende con el tiempo a cerrarse en la estabilidad de nuestro mundo vital ordinario. En la medida que "el encuentro desencadena paso a paso los acontecimientos que configuran una historia real y las emociones que apasionan una vida real" (Jankélévitch, 1989, p. 36), en la aventura amorosa se intenta encontrar con el tiempo un suelo que acoja este impulso de un nuevo comienzo, es decir, una topología desde la cual se pueda erigir un nuevo hogar en el mundo de la vida del hombre.

Esta tensión no solo afecta la aventura amorosa. Ella es también una nota característica de la aventura del pensamiento. En este sentido, podemos decir ahora que la aventura ha sido una nota particular de la historia de la metafísica. En efecto, el deseo de saber aquello que desborda nuestros propios límites puede ser leído entonces como la aventura más riesgosa de Occidente. Antes de ser una mera fatalidad ${ }^{49}$, el constante regreso a este deseo es ciertamente expresión, más allá de su carácter aparentemente recesivo, de la destinée propia del pensamiento occidental, en cuanto constituye lo que Kant denominó de manera acertada nuestra más originaria Naturanlage. Así como hay diferentes formas de retornar a una amada y de erigir para ella todo un nuevo mundo, en el cual se pueda realizar a plenitud la dicha que su presencia trae, el regreso a la tan deseada metaphysica naturalis se ha cumplido en la historia de Occidente de manera múltiple. Por ejemplo, tomando distancia del estancamiento dogmático de la metafísica de su época, Kant emprende el retorno a la amada levantando un nuevo mundo para ella: la moralidad fundada en la libertad ${ }^{50}$. Aquí este retorno implica empero lle-

49 En su conferencia La superación de la metafísica, Heidegger (1994) señala que "la metafísica, en todas sus figuras y en todos sus niveles históricos, es una única fatalidad [Verhängnis: horizonte inevitable], pero quizás también la fatalidad necesaria de Occidente y el presupuesto de su dominio planetario. La voluntad de este dominio reobra sobre el centro de Occidente, un centro desde el cual, a su vez, una sola voluntad se opone a la voluntad" (p. 69).

50 Este retorno lleva consigo, obviamente, una radical transformación de la metafísica históricamente dada, pues "Kant se encontró prácticamente solo en una época en la que la metafísica, como él dice, era un nombre con mala fama, cosa que, sin embargo, fue lo que precisamente le movió a dar a su primera obra de filosofía moral el disuasorio título de Fundamentación de la metafísica de las costumbres. Si es cierto que los pensamientos que, en el sentido que sea, forman parte del campo de la metafísica, son tan imprescindibles como indemostrables, entonces lo que cabe esperar es, precisamente, esto: el conocimiento será llevado hacia un progreso y una sutileza cada vez mayores, sutileza que pone en suspenso tales pensamientos. Y del mismo modo, aunque no al mismo paso, se transformará el entendimiento consigo acerca del fundamento y contenido de lo imprescindible. Ambos procesos, en su mutua implicación, pueden y deben ser considerados como 
var al altar a la amada, cubriéndola así de una nueva legalidad. En efecto, el retorno kantiano al destinée constitutivo de nuestro pensamiento muestra que "de aquello de lo que el ser humano no puede prescindir forma parte, en primer lugar, una vida que se libera de una necesidad (Not) que no es destino (Schicksal)" (Henrich, 2005, p. 107), pero que configura, no obstante, nuestro territorio mundo-vital más propio.

Otro camino posible de retorno es, sin duda, la actitud heideggeriana frente a la metafísica. Denunciado ahora que la historia de la metafísica ha consistido realmente en la historia del olvido del ser, olvido que se ha incrementado de manera abismal en la Modernidad incluso en manos de Nietzsche -quien buscaba alcanzar la superación de todo pensamiento metafísico-, Heidegger emprende desde su famosa analítica existencial del Dasein la tarea de retornar a aquello olvidado, levantando para ello con una clara decisión histórica la pregunta fundamental por el sentido del ser. El retorno a esta pregunta Heidegger lo quiere realizar como un verdadero hito de viraje $\mathrm{e}^{51}$ en la Seinsgeschichte, pues solo como el acontecimiento más originario de apertura del ser en su más constitutiva historicidad se podrá donar la significatividad del ser, el claro. De esta manera, se realizaría aquí la verdadera torsión de la metafísica ${ }^{52}$, en la medida que su retorno

Ilustración, siempre que no se otorgue ningún valor a los excéntricos tonos que ven un programa de destrucción en esta noble palabra, en este anhelo de luz" (Henrich, 2005, pp. 103-104).

51 Para Heidegger (2001), un hito es "una estancia y parada en el camino que conduce a la pregunta única por el ser [...]. El camino hacia esa estancia impide describirla como algo que está delante de antemano. El que trata de llegar hasta ella solo puede recurrir al incansable esfuerzo por explicar y localizar (encontrar en su lugar) aquello que en un tiempo la palabra ser desveló como aquello que había que pensar y que tal vez algún día volverá a velar como algo ya pensado" (pp. 12-13). En este sentido, el hito de viraje hacia la historia del ser implica poder situar "la historia en el ámbito del acontecer, en lugar de pensar la historia según su proveniencia esencial desde el destino. Pero, destino es esencialmente destino del Ser, de manera tal que lo Ser mismo se destina y, en cada caso esencia como destino y, conforme a ese, se transmuta destinadoramente. Si acontece-apropia [ereignet] una transmutación en el Ser, esto es, ahora, en la esencia de lo dis-puesto, entonces esto no dice, de ninguna manera, que sea eliminada la técnica, cuya esencia reposa en lo dispuesto. Ella no es ni derribada ni destrozada" (Heidegger, 1993, p. 144).

52 El viraje que implica la superación de la metafísica es, para Heidegger (1994), "el acaecimiento propio en el que el ser mismo está en torsión. Ante todo, superación no quiere decir el arrumbamiento que saca a una disciplina del horizonte de intereses de la 'cultura' filosófica. La palabra 'Metafísica' está pensada ya como sino de la verdad del ente, es decir, de la condición de ente, entendida en cuanto acaecer propio todavía oculto pero sobresaliente, a saber, del olvido del ser" (p. 63). 
sería al mismo tiempo su cumplimiento histórico. Pero así como "a la naturaleza le place ocultarse”, como lo anota magistralmente Heráclito (DK 22-B, 123), Heidegger busca en su reiterativo viraje ocultar siempre a su amada. Ya no quiere llevarla al altar, sino mantenerla en su ocultamiento.

Como vemos, levantar una nueva legalidad del mundo para llevar allí a la amada, a la que regresamos permanentemente, u ocultarla en el claro siempre venidero pero nunca asible de la historia del ser, son dos caminos posibles para tratar con lo mismo, a saber: con aquello que somos nosotros mismos y que, no obstante, es inconceptualizable. Esto a lo que retornamos siempre es lo abierto que se vuelve palabra y que en nuestro mundo histórico vital adquiere la consistencia de una narración que impide que nos perdamos irremediablemente en el paso del tiempo, pues siempre nos da aliento para sobrevivir. A su manera, y tomando distancia tanto de la estrategia de Kant como de la de Heidegger, Blumenberg emprende también el arduo peregrinaje de retorno a la amada. Es muy distinta su estrategia. No busca ya erigir una nueva normatividad para ella, ni ocultar su decidido compromiso con sus más íntimas posibilidades. Más bien, en medio de tiempos sombríos como los nuestros, se propone dormir simplemente en ella, porque el sueño $0^{53}$ es realmente el lugar donde el mundo se abre y se transforman todos nuestros más íntimos temores. Esta transformación es, en efecto, nuestra posibilidad más propia de trastocar lo estancado en la historia y abrirlo en su significatividad, para proyectar así un nuevo cielo y una nueva tierra. Esta proyección es, justamente, el poder de la metáfora.

Para terminar, podemos afirmar ahora que reconstruir el proceso de constitución histórica de los conceptos y de las formaciones sistemáticas es la meta del análisis inmanente de la descripción histórica del proceso técnico de

53 Para Blumenberg, el sueño es el verdadero intérprete de nuestras inclinaciones más profundas, pues es la forma como afirmamos nuestra posibilidad de sobrevivir. Pero el hombre como animal huidizo se refugia siempre en aquello que le da la posibilidad de estar distante de lo que lo aqueja; por esta razón, "el sueño significa una pura impotencia respecto a lo soñado, una desconexión completa del sujeto y de la capacidad de disponer de sí mismo en medio de imágenes extremadamente proclives a un estado de angustia; pero, al mismo tiempo, el sueño es un puro dominio de deseos, que hace del despertar una suma de todos los desencantos, por muchas censuras a las que haya estado sometido el mecanismo psíquico del sueño. Volar en sueños -fórmula nietzscheana para designar algo que él considera una prerrogativa suya- es la metáfora del fútil realismo presente en la más intensa ilusión de realidad" (Blumenberg, 2003c p. 18). 
configuración de las metáforas. Como lo hemos indicado antes, Blumenberg, al igual que Derrida, despliega su metaforología como respuesta al desafío kantiano de preservar la metaphysica naturalis más allá de los resultados de la crítica de la razón pura. Esta empresa se realiza también como una arqueología analítica del logos y de sus posibilidades en los giros retóricos. La descripción de la historia de este proceder técnico se aparta, de este modo, del lenguaje histórico enredado en la historia de los conceptos y se propone, más bien, mostrar la lógica histórico-efectiva de las consecuencias de los tropos como una estructura a priori del discurso. En lugar de afirmar la jerarquía del concepto frente a las figuras simbólicas y los rodeos metafóricos, Blumenberg enfatiza la primacía del discurso traslaticio para mostrar lo que se encuentra a la base de nuestras preocupaciones más fundamentales. En este sentido, las metáforas son realmente el medio más propio de la realización histórica de nuestra Naturanlage, pues "la metafísica se nos mostró como metafórica tomada al pie de la letra” (Blumenberg, 2003a, p. 257). Más allá de la desconfianza escéptica frente a la metafísica, el retorno a la amada, de la que habla Kant al final de la Crítica de la razón pura, se realiza en todo momento como un viraje metaforológico abierto en sus posibilidades históricas, pues solo así el hombre encuentra su lugar en el proceso de civilización (Zill, 1999, p. 165).

Referencias

Aristóteles. (1994). Metafísica. Madrid: Gredos.

Blumenberg, H. (1967). Nachbemerkung zum Berich über das Archiv für Begriffsgeschichte. Jahrbuch der Akademie der Wissenschaften und Literatur Mainz, pp. 79-80.

Blumenberg, H. (1971). Beobachtungen an Metaphern. Archiv für Begriffsgeschichte, 15, pp. 161-214.

Blumenberg, H. (1981). Lebenswelt und Technisierung unter Aspekten der Phänomenologie. En: Wirklichkeiten in denen wir leben (pp. 7-54). Stuttgart: Reclam.

Blumenberg, H. (1995). Naufragio con espectador. Paradigma de una metáfora de la existencia. Madrid: Visor. 
Blumenberg, H. (2001a). Licht als Metapher der Wahrheit. Im Vorfeld philosophischer Begriffsbildung. En: A. Haverkamp. (Ed.). Ästhetische und metaphorologische Schriften (pp. 139-171). Frankfurt: Suhrkamp.

Blumenberg, H. (2001b). Anthropologische Annährungen an die Aktualität der Rethorik. En: A. Haverkamp. (Ed.). Ästhetische und metaphorologische Schriften (pp. 406-431). Frankfurt: Suhrkamp.

Blumenberg, H. (2002). La posibilidad de comprenderse. Obra póstuma. Madrid: Editorial Síntesis.

Blumenberg, H. (2003a). Paradigmas para una metaforología. Madrid: Trotta.

Blumenberg, H. (2003b). Conceptos en historias. Madrid: Editorial Síntesis.

Blumenberg, H. (2003c). Trabajo sobre el mito. Barcelona: Paidós.

Blumenberg, H. (2008). La legitimación de la Edad Moderna (edición corregida y aumentada). Valencia: Pre-Textos.

Blumenberg, H. (2013a). Historia del espiritu de la técnica. Valencia: Pre-Textos.

Blumenberg, H. (2013b). Teoría del mundo de la vida. México: Fondo de Cultura Económica.

Campe, R. (2009). Von der Theorie der Technik zur Technik der Metapher. Blumenbergs systematische Eröffnung. En: A. Haverkamp \& D. Mende. (Eds.), Metaphorologie. Zur Praxis von Theorie (pp. 283-315). Frankfurt: Suhrkamp. Creutzig, M. (2009). Neue Großhandelsbetribslehre. Frankfurt: Peter Lang Verlag. Deleuze, G. (1988). Diferencia y repetición. Madrid: Ediciones Júcar.

Derrida, J. (2010). De la gramatología. México: Siglo XXI Editores.

Gehring, P. (2014). Metapher. En: R. Buch y D. Weidner. (Eds.), Blumenberg lesen. Ein Glossar (pp. 201-213). Berlin: Suhrkamp.

Haverkamp, A. (2007). Metapher. Die Ästhetik in der Rhetorik. Bilanz eines exemplarischen Begriffs. München: Wilhelm Fink Verlag.

Heidegger, M. (1993). La vuelta [Die Kehre]. En: Ciencia y técnica (pp. 143155). Santiago de Chile: Editorial Universitaria.

Heidegger, M. (1994). Conferencias y artículos. Barcelona: Ediciones del Serbal. Heidegger, M. (2001). Hitos. Madrid: Alianza Editorial.

Heindereich, F. (2005). Mensch und Moderne bei Hans Blumenberg. München: Wilhelm Fink Verlag. 
Henrich, D. (2005). Vida consciente. Madrid: Editorial Síntesis.

Heráclito. (2000). Fragmentos. En: C. Eggers. (Ed.). Los filósofos presocráticos. Vol. 1 (pp. 309-397). Madrid: Gredos.

Jankélévitch, V. (1989). La aventura, el aburrimiento, lo serio. Madrid: Taurus.

Kant, I. (2012). Crítica del discernimiento, o de la facultad de juzgar. Madrid: Alianza Editorial.

Kant, I. (2009). Crítica de la razón pura. México: Fondo de Cultura Económica.

Klein, C. (2006). Manual de mineralogía. Barcelona: Editorial Reverté.

López, J. (2013). La vida revirada. Un reportaje especulativo. Derrida, Blumenberg y alrededores. En: J. Villacañas. (Ed.), Blumenberg: la apuesta por una ilustración tardia. Anthropos. Cuadernos de cultura crítica y conocimiento, (239), pp. 107-138.

Müller, O. (2005). Sorge um die Vernunft. Hans Blumenbergs philosophische Anthropologie. Paderborn: Mentis.

Renn, J. (1999). Die Verbindlichkeit der Geschichten. Die Geschichte der Neuzeit als eine Genealogie narrativer Geltung. En: F. Wetz y H. Trimm. (Eds.), Die Kunst des Überlebens. Nachdenken über Hans Blumenberg (pp. 307326). Frankfurt: Suhrkamp.

Stoellger, Ph. (2000). Metapher und Lebenswelt. Hans Blumenbergs Metaphorologie als Lebenswelthermeneutik und ihr religionsphänomenologischer Horizont. Tübingen: Mohr Siebeck.

Torregroza, E. (2014a). Reacciones hermenéuticas ante un barco que se hunde. En: J. Villacañas (Ed.), Blumenberg: la apuesta por una ilustración tardía. Anthropos. Cuadernos de cultura critica y conocimiento, (239), pp. 159-167.

Torregroza, E. (2014b). La nave que somos. Hacia una filosofia del sentido del hombre. Bogotá: Editorial Pontificia Universidad Javeriana.

Tremmel, F. (2013). Rothacker, E. En: Th. Bedorf. (Ed.), Die deutsche Philosophie im 20 Jabrbundert (pp. 243-244). Darmstadt: Wissenschaftliche Buchgesellschaft.

Villacañas, J. (2014). Un caso de metaforología: la escena originaria. En: J. Villacañas (Ed.), Blumenberg: la apuesta por una ilustración tardia. Anthropos. Cuadernos de cultura critica y conocimiento, (239), pp. 57-70. 
Zill, R. (2014). Anekdote. En: R. Buch y D. Weidner. (Eds), Blumenberg lesen. Ein Glossar (pp. 26-42). Berlin: Suhrkamp.

Zill, R. (1999). Wie die Vernunft es macht... Die Arbeit der Metapher im Prozeß der Zivilisation. En: F. Wetz \& H. Trimm. (Eds.), Die Kunst des Überlebens. Nachdenken über Hans Blumenberg (pp. 164-183). Frankfurt: Suhrkamp. 
